\title{
Review of sub-3 nm condensation particle counters, calibrations, and cluster generation methods
}

\section{Kangasluoma, Juha}

2019-11-02

Kangasluoma , J \& Attoui , M 2019 , ' Review of sub-3 nm condensation particle counters, calibrations, and cluster generation methods ' , Aerosol Science and Technology , vol. 53 , no. 11 , pp. 1277-1310 . https://doi.org/10.1080/02786826.2019.1654084

http://hdl.handle.net/10138/318568

https://doi.org/10.1080/02786826.2019.1654084

unspecified

acceptedVersion

Downloaded from Helda, University of Helsinki institutional repository.

This is an electronic reprint of the original article.

This reprint may differ from the original in pagination and typographic detail.

Please cite the original version. 
Review of sub-3 nm condensation particle counters, calibrations and cluster generation methods

J. Kangasluoma ${ }^{1,2}$, M. Attoui ${ }^{3}$

${ }^{1}$ Institute for Atmospheric and Earth System Research/Physics Faculty of Science, University of Helsinki, Helsinki, Finland

2 Aerosol and Haze Laboratory, Beijing Advanced Innovation Center for Soft Matter Science and Engineering, Beijing University of Chemical Technology, Beijing, China

${ }^{3}$ LISA, UMR7583, Université Paris-Est-Créteil, Université de Paris, Institut Pierre Simon Laplace (IPSL), Créteil, France

\section{Abstract}

This review discusses the developments in aerosol instrumentation that have led to the current vapor condensation based instruments capable of detecting sub-3 nm particles. We begin from selected reports prior to year 1991, which have advanced the technology or understanding in condensation particle counting toward sub-3 nm sizes, and continue to more in depth review of the past efforts after 1991. We discuss how the developments in the calibration methods have progressed the development of particle counting techniques, and review briefly the sub-3 nm calibration experiments and cluster production methods used in calibration experiments. Based on these reviews, we identify several technological and scientific advances for the future to improve the accuracy, understanding and technology of sub-3 nm particle counting.

\section{Introduction}

In gas-to-particle conversion vapors undergo chemical reactions and clustering, producing molecular clusters that grow to larger sizes via vapor condensation and coagulation. Such process takes place in the atmosphere, and in many industrial and nanomaterial synthesis processes (Ahonen et al. 2017; Alanen et al. 2015; Cai et al. 2017b; Carbone et al. 2016; Feng et al. 2016; Hietikko et al. 2018; Jiang et al. 2011c; Kangasluoma et al. 2015b; Kirkby et al. 2011; Kirkby et al. 2016; Kuang et al. 2012a; Kulmala et al. 2013; Maisser et al. 2015a; Nosko et al. 2017; Rönkkö et al. 2017; Wagner et al. 2017; Wang et al. 2017a). The need to understand and quantify these processes starting from the smallest molecular clusters has led to development of several particle counting instruments and methods to verify their operation. Electrical methods are used in some cases to count the sub-3 nm particles, while a condensation particle counter (CPC) is the most commonly used detector due to its extremely low background noise levels. In this review, we focus on the CPCs capable for sub-3 nm particle counting and the preceding developments, the CPC calibrations and cluster production methods for the calibrations.

CPC refers to a technique, in which nanoparticles are grown by condensing a selected vapor onto the particle. At minimum, the particles have to grow to around $300 \mathrm{~nm}$ in diameter to scatter light from a laser source, and these scattered light pulses from individual particles are counted with a photodetector. There are several aspects to consider in the instrument design when aiming for the detection of sub-3 nm particles using the CPC technique. The fluid supersaturation has to be high enough so that when the particles are exposed to the supersaturated fluid, condensational growth is activated (activation). The simplest model for predicting the required supersaturation is the Kelvin equation, describing the saturation vapor pressure over curved surfaces. Later on Fletcher constructed a heterogeneous nucleation theory for a nuclei growing on a curved particle surface (Fletcher 1958). Reaching sufficient supersaturation is often not a practical problem, as it is mostly controlled by the temperature difference $(\Delta \mathrm{T})$ between the heated and saturated flow, and its subsequent cooling, which in practical applications are in easily achievable range $\left(0-100^{\circ} \mathrm{C}\right)$. If the fluid supersaturation is high 
enough, vapor condenses also homogeneously. Preferably, the supersaturation is kept low enough to not produce droplets via homogeneous vapor nucleation to ensure that each counted pulse is originating from heterogeneously formed and grown droplet. Often the activation of sub-3 nm particles requires a supersaturation that is close to the homogeneous nucleation limit, and in some cases exceeds that, for example when a CPC is tuned to its limits to detect the smallest particles possible. Then, a suitable supersaturation is limited by the signal-to-noise ratio (ratio of droplet count produced by heterogeneous over homogeneous nucleation) in a given experiment.

It is also important to account for diffusional transport losses when evaluating the performance of sub-3 nm CPCs. As usually assumed, once a particle collides to the transport tube wall due to random Brownian motion, it is permanently lost there. This means that in the instrument design, the transport distance and time from the inlet to the supersaturated region must be minimized. Similarly, in practical particle concentration monitoring experiments, the length of transport lines must be minimized in order to ensure that the highest possible fraction of the particles reach the instrument inlet.

Other important parameters in the instrument design are, for example, selection of the working fluid, saturator and condenser geometry, flow rates, and capability to detect high particle concentrations accurately. The working fluid determines the required temperatures while (mainly) flow rates constrain minimum length for the saturator and condenser. Some sub-3 nm CPCs utilize relatively high flow rates, thus the saturator and condenser geometry has to be such that there is enough time for a flow to become fully saturated, and on the other hand the peak supersaturation has to take place early enough in the condenser to give enough time for droplet growth. The concentrations of small clusters are often high during their formation process, so the CPC should be capable of detecting concentrations at least up to $10^{5} \mathrm{~cm}^{-3}$.

To date, three techniques to create fluid supersaturation in a CPC have been introduced: adiabatic expansion, adiabatic and turbulent mixing of two flows, and laminar flow diffusion, all of which have been applied to sub-3 nm particle detection. Adiabatic expansion technique is semicontinuous and instrumentally more complex than the other two methods, while, on the other hand, it gives accurate control over the supersaturation via accurate control of uniform temperature field and expansion ratio of the chamber. Thus, it has remained mostly a valuable laboratory instrument in research of physical processes governing heterogeneous nucleation. Turbulent mixing of a heated and saturated flow with another cooler flow containing the sample particles allows continuous measurements. When equipped with adequate flow control system, it makes possible fast changes in the supersaturation, and has the advantage that the aerosol does not need to be brought through the heated saturator. In the turbulent mixing method, accurate determination of the magnitude and field of supersaturation is a challenge due to turbulence taking place in very small dimensions and potential vapor losses that can be hard to determine. Continuous laminar diffusion CPCs, of which operation principle is based on the relative difference in the rate of diffusion between the working fluid and heat, are the most common CPCs due to their (relative) technological simplicity.

The previously listed parameters are the first requirements to perform sub-3 nm particle concentration measurements with CPCs. More parameters of interest and techniques are included when the size distribution of sub-3 nm particles are measured. Generally, these techniques can be split into four: the electrical mobility spectrometer (EMS) method, CPC battery (CPCb) method, supersaturation scan method (SS) and pulse height analysis (PHA) method. In this review, we discuss these methods from the CPC point of view. The CPCb method is realized with multiple CPCs but with different smallest detectable particle diameters (cut-off diameter, the diameter at which 50\% of particles are detected. From here onward: cut-off), while in the SS method by using a single CPC, of which one parameter (flow or temperature) is varied to vary the cut-off. The PHA method relies on the supersaturation profile along the particle trajectories in the CPC condenser: smaller particles activate deeper in the condenser, having less time for condensational growth. Thus, the final droplet diameter and scattered pulse height in the optics is dependent on the initial particle diameter. In an EMS, the particles are charged often with a 
bipolar radioactive source, then classified using a differential mobility analyzer (DMA), and the sizeclassified particles are detected using a CPC.

In this review, we discuss the above mentioned techniques in the context of sub-3 nm particle detection. We start with discussion on some selected reports prior to 1991 that we consider as significant advances toward sub-3 nm particle detection. Next, more in depth review is given for developments after 1991, when the ultrafine CPC was introduced by Stolzenburg and McMurry. An important part of the CPC development work has been the development of the calibration methods, and they are reviewed after the CPCs. Part of the calibration method discussion are the sub- $3 \mathrm{~nm}$ particle production methods, which are also briefly reviewed. In the light of these reviews, we finally discuss some future challenges that would improve the CPC based measurements and our capabilities for characterizing the sub-3 $\mathrm{nm}$ particles and their dynamics more accurately. We apologize for any omissions or biases in the review.

\section{Milestones prior to 1991}

The intriguing historical review on CPCs by McMurry (2000) cites major developments and prior reviews through the end of the twentieth century. This review, with its focus on sub-3 nm detection, begins by noting the landmark publications on early CPC developments considered capable of sub-3nm detection. We begin this review with notes of few landmark publications on early CPC developments and related instrumentation prior to the CPCs that are commonly considered as $3 \mathrm{~nm}$ or sub-3 nm CPCs. We briefly discuss the first CPC experiments with the three main designs, then notes on CPC detection efficiency on particle size and particle chemical composition, absolute CPC concentration calibration, comparisons to theory, ultrafine CPC workshop and CPC condenser modeling, which all are crucial steps in progressing the CPC technology toward sub-3 nm particle detection.

The first CPC experiments were conducted by Coulier (Coulier 1875a; b) and Aitken (Aitken 1880a; b), and further continued by Wilson (Wilson 1897; 1899). In their expansion type instruments, a known volume containing air saturated with water vapor is expanded to achieve well-defined water supersaturation. The supersaturation was accurately controlled by varying the expansion ratio of the chamber. The grown droplets were manually counted by eye due to lack of optical technology. Already these first expansion type CPCs would have been able to grow and detect sub- $3 \mathrm{~nm}$ particles were they present in the expansion chambers, since they were able to activate and grow ions produced by the Xrays, as well as produce homogeneously formed droplets from water. It took a century to develop the necessary instrumentation to generate and size-classify the suitable particle populations to verify the size dependent fraction of activated particles in such experiments. The second commonly used method for creating vapor supersaturation, turbulent mixing of warm saturated flow with a second, cooler flow containing the aerosol particles, was invented by Kogan and Burnasheva (1960). Their CPC was operating with dibutyl phthalate, and the grown droplets were manually counted. The work of Bricard et al. (1976) and Sinclair and Hoopes (1975) showed the third method for exposing particles to supersaturation: the continuous laminar flow diffusion based CPC. Their CPCs operated with water, methanol, ethanol or butanol as condensing liquid. Particle detection in the CPC of Sinclair was based on light intensity attenuation, while the CPC of Bricard utilizes single particle counting thanks to the design of the optical head (El Golli et al. 1975). The saturator-condenser-optics design of the Bricard $\mathrm{CPC}$ resembles very closely the current conventional $10 \mathrm{~nm}$ laminar flow $\mathrm{CPCs}$, which, as such, has been also shown to be capable for sub-3 nm particle detection.

Before aerosol sizing with a DMA and concentration measurement with an aerosol electrometer (AEM) were available, most CPC calibration experiments were conducted against the Pollak counter (Pollak and Daly 1957), which was thought to give a reliable number concentration measurement. Many experiments focused on measuring atmospheric particle number concentration, whereas in laboratory experiments the CPCs were operated at the limit of homogeneous droplet formation or ion induced nucleation. Therefore, it may have been thought that the CPCs can detect all particles above the Kelvin 
diameter at a supersaturation slightly below the limit of homogeneous nucleation. The Kelvin diameter gives a theoretical prediction for the equilibrium vapor pressure over a curved surface, i.e. what is the smallest particle size onto which liquid condenses at a given supersaturation. However, it does not take into account the properties of the particle, like its solubility and wettability. For most of the liquids that can be considered as a CPC working fluid, the Kelvin diameter is from 1.7 to $4 \mathrm{~nm}$ at supersaturation just low enough not to produce homogeneously nucleated droplets. Magnusson and coworkers found out that glycerol and water give the smallest Kelvin diameter while Iida and coworkers showed that diethylene glycol is the best working fluid both theoretically and experimentally (Iida et al. 2009; Magnusson et al. 2003).

The first CPC calibration using a DMA and an aerosol electrometer (AEM) was published by Liu and Pui (1974) in their landmark paper. They were the first ones to combine a Faraday cage particle filter to an analog electrometer, providing a new absolute concentration reference. For accurate concentration measurement, the AEM requires that the test particles are singly charged. From the methodological point of view, their experimental setup is identical to the standard CPC calibration setups used today: Particle generator, charger, DMA, and comparison of AEM and CPC signals for size selected particles. In their setup, particles were generated by nebulizing $\mathrm{NaCl}$, heating it up in a furnace, and subsequently cooling it down to produce high particle concentrations also in the smallest size range. Using this setup, Liu and Pui calibrated Environment/One model Rich 100 CPC and General Electric CPC down to particle diameter of $11 \mathrm{~nm}$. They concluded that there is no size dependency on the CPC detection efficiency down to $25 \mathrm{~nm}$, suggesting relatively well designed CPC in terms of particle transport and diffusion losses. Thanks to the introduction of a DMA and an electrometer, more accurate CPC characterizations became possible.

Notes on the size dependency of CPC detection efficiency were published by Pedder (1971; 1974), who studied the diffusion characteristics of particles inside the Pollak counter. After Pedder, several other researchers examined the size dependent detection efficiency of CPCs, which are reviewed by Sinclair (1981). Notably, Liu and Kim (1977) used their DMA and electrometer based calibration setup to calibrate the expansion type GE CPC in the size range of 10 to $80 \mathrm{~nm}$, finding clear decrease in the detection efficiency at sizes below $40 \mathrm{~nm}$. The conclusion was clear; at sizes below $50 \mathrm{~nm}$ the CPCs do not count $100 \%$ of the particles, and the size dependent particle detection efficiency must be characterized for accurate number concentration measurements. It became evident that the Kelvin theory alone does not predict the CPC cut-off.

With similar calibration setup as Liu and Pui, Madelaine and Metayer (Madelaine and Metayer 1980; Metayer and Madelaine 1980) presented cut-off curves for a CPC operated with butanol (CPC detection efficiency as a function of the particle diameter) for sulfuric acid, sodium chloride and vanadium oxide. Their results suggested that the butanol CPC cut-off is dependent on the particle chemical composition.

In his thesis, Brockmann describes experiments that lead later on to the development of the pulse height analysis (PHA) CPC (Brockmann 1981). Among other things, he was modifying the detection threshold of the optical white light detector. The pulse heights obtained using the TSI 3020 showed clear increase when the particle size range increased from 3 to about $20 \mathrm{~nm}$.

An impressive theoretical analysis and set of experiments were published in 1985-1986 by Porstendörfer et al. (1985) and Scheibel and Porstendörfer (1986a; 1986b). They performed calibrations for three water-based CPCs, a photographic CPC, and two General Electric expansion CPCs, using size classified $\mathrm{NaCl}$ and $\mathrm{Ag}$ particles, studied the effect of particle charge and composition on the detection efficiency, and compared their results to theoretical predictions given by the Kelvin model and heterogeneous nucleation theory by Fletcher (1958). Summarizing their important conclusions: it is impossible to generalize the cut-off for all CPCs because it depends on the vapor saturation ratio and especially on particle surface properties, which originate from the particle chemical composition, and is theoretically handled with the liquid-particle contact angle. The experimental results show that $\mathrm{NaCl}$ particles are detected at lower supersaturation than the Kelvin prediction, while for the Ag particles it is 
the opposite, and that the detection efficiency does not depend on particle charge. For the insoluble particles, agreement was found between the Fletcher theory and experiments. Further, they discuss the importance of sampling based on experiments and theory, concluding that in the current CPC designs, the detection efficiency of $2 \mathrm{~nm}$ particles can be very low, even to below $10 \%$, due to particle diffusion losses even if the vapor saturation ratio is large enough. This publication lead to a discussion on the role of particle solubility on the critical supersaturation, which is possibly one of the parameters determining the cut-off for various liquid-particle composition pairs (Scheibel and Porstendörfer 1986c; Stolzenburg 1986).

Results from an ultrafine particle counter workshop (interestingly including all three types of CPCs) are reported by Bartz et al. (1985) in which four different CPCs were compared: water based expansion CPC by Niesser and Helsper (1985), commercial laminar flow butanol CPC TSI 3020 by Agarwal and Sem (1980), conductively cooled ultrafine (CCU) butanol CPC by Stolzenburg and McMurry (1991) (the prototype CPC leading to the commercial TSI ultrafine CPCs) and mixing type ultrafine (MTU) CPC by Kousaka et al. (1982) operated with water or hexanol. The TSI 3020, MTU CPC and CCU CPCs showed detection efficiencies of $0.06,0.6$ and 0.83 , respectively, for $3 \mathrm{~nm} \mathrm{NaCl}$ particles. The publication reports also generation of neutralized particles and measurement of their respective detection efficiency, however, without findings of any significant effect of charge nor charge sign on the particle detection. On the optics and electronics, the authors noted: When separate pulse counting electronics were connected to the TSI Model 3020 photodetector, the counting efficiency at 3 $\mathrm{nm}$ was $0.28 \pm 0.04$. This challenge was solved by TSI in the TSI 3022 and ultrafine 3025 by introducing laser optics instead of white light and microcontroller, and such problems do not exist anymore. The workshop also clearly demonstrated the importance of the instrument design in sampling and detection of sub-3 nm particles.

In 1990, Ahn and Liu (1990a; 1990b) presented measurements on the grown droplet size downstream of the condenser, as well as a flow dynamic model of the supersaturation profile inside the CPC condenser. They noticed a clear connection between the initial particle size and grown droplet size, and that these droplets can be sized based on the height of the scattered light pulse. The explanation for this observation is that the smaller particles penetrate deeper into the supersaturation field before the growth begins, thus having less time to grow than the larger particles. This is the basis of the pulse height analysis (PHA) CPCs that have been applied in sub-3 nm sizing also.

Review of past efforts on sub-3 nm particle detection

\section{Laminar flow butanol CPCs}

Design line of the Stolzenburg ultrafine CPC

One of the main milestones in the detection of sub-3 nm particles was published in 1991, when Stolzenburg and McMurry (1991) reported their ultrafine CPC, which was modified from the TSI 3020 (Figure 1). Part of the work of Stolzenburg was initially published in a book chapter already in 1984 (Stolzenburg and McMurry 1984), where they also present the first computational fluid dynamics model of the CPC condenser. The CPC is the prototype of the ultrafine CPC series TSI 3025A, 3776 and 3756 and on most parts also the DEG based TSI 3777, and its design served as the basis for many subsequent CPC prototypes.

The instrument design included various improvements to the previous laminar CPCs with respect to $3 \mathrm{~nm}$ particle detection. The predecessor of this prototype is the CPC of Wilson et al. (1983), which introduced the concept of sheath flow in the condenser (to initially minimize the effect of ambient pressure on detection efficiency). Similar to previous TSI 3022, the prototype ultrafine CPC can be operated at inlet flow rate of 0.3 or $1.5 \mathrm{~L} \mathrm{~min}^{-1}$. When using $1.5 \mathrm{~L} \mathrm{~min}^{-1}$ inlet flow rate, $0.3 \mathrm{~L} \mathrm{~min}^{-1}$ is extracted with a sub-sampling design from the main transport flow centerline, and $1.2 \mathrm{~L} \mathrm{~min}^{-1}$ is 
discarded. The extracted aerosol flow is subsequently split to two: $0.03 \mathrm{~L} \mathrm{~min}^{-1}$ aerosol flow going through a capillary that is again extracted from the core of the flow and fed to the condenser centerline, and $0.27 \mathrm{~L} \mathrm{~min}^{-1}$ sheath flow that is filtered and saturated with butanol, and finally brought back to the condenser around the aerosol flow. Thus, dilution of $1 / 10$, which is coupled to relatively low aerosol flow rate, allows single particle counting above concentrations of $10^{5} \mathrm{~cm}^{-3}$. The flow rate in the optics is always $0.3 \mathrm{~L} \mathrm{~min}$ mo $^{-1}$ out which aerosol flow is $0.03 \mathrm{~L} \mathrm{~min}^{-1}$ regardless of the operation conditions.

The aerosol transport from the inlet to the condenser consists of two sub-sampling sections, in which a portion of the aerosol flow is subsampled from the flow centerline. This preserves the particle concentration in the condenser close to the initial sampled concentration and minimizes the particle transport losses. In the previous fine CPCs, the particles had to travel through a long and heated saturator, which causes significant particle losses due to particles diffusing to the walls. Further, the capillary of the second subsampling feeds the particles to the centerline of the condenser, and together with a butanol saturated sheath flow around the aerosol flow, the particles are exposed to the highest supersaturation region in the centerline of the condenser. This design makes the cut-off curve sharper compared to nonsheathed fine CPCs, as the particles are exposed to a more uniform supersaturation profile. A major fraction of the particle diffusion losses take place in the capillary needle, which can be determined theoretically. With all these technological advances, this CPC reaches 50\% detection efficiency at $3 \mathrm{~nm}$ (Figure 2). Further milestones of their research were the reasonable agreement of a theoretical condenser and particle activation model of the CPC detection efficiency in comparison to the experiments, and detailed handling of the data, leading to the final detection efficiency values.

Overall, the work of Stolzenburg and McMurry at University of Minnesota created tool for aerosol scientists to study directly and in-situ airborne ultrafine particle processes, which were unreachable previously. Much of the progress on the design of the CPCs for detecting sub-3 nm particles is based on their work. TSI developed Stolzenburg and McMurry's sub-3 nm CPC into a commercial instrument that was widely used by other groups. Subsequently, many other groups began developing new tools for measuring sub-3 nm particles, and studying phenomena in this size range.

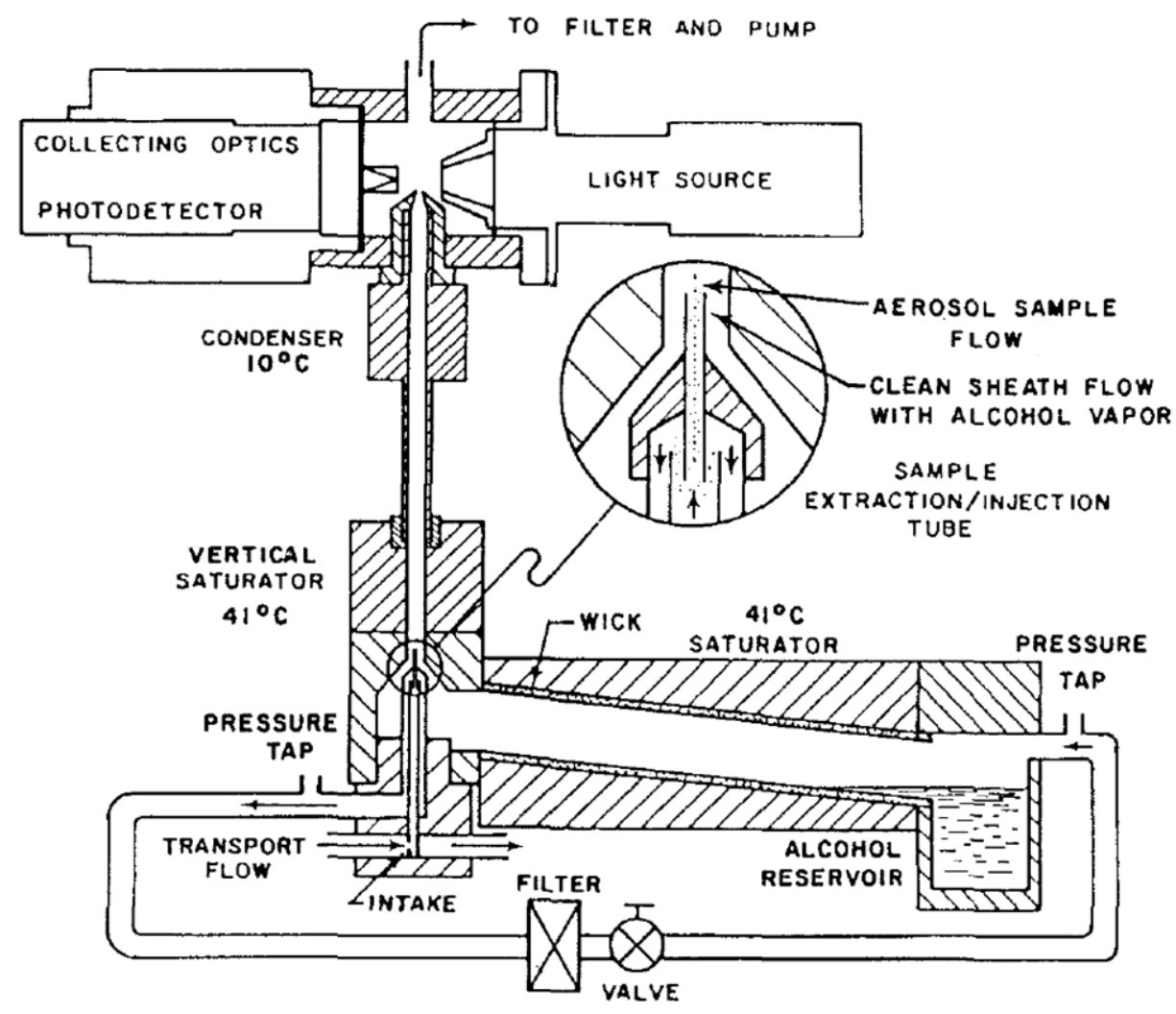

Figure 1. The ultrafine condensation particle counter by Stolzenburg and McMurry (1991) (Reproduced with permission of AAAR and AS\&T). 


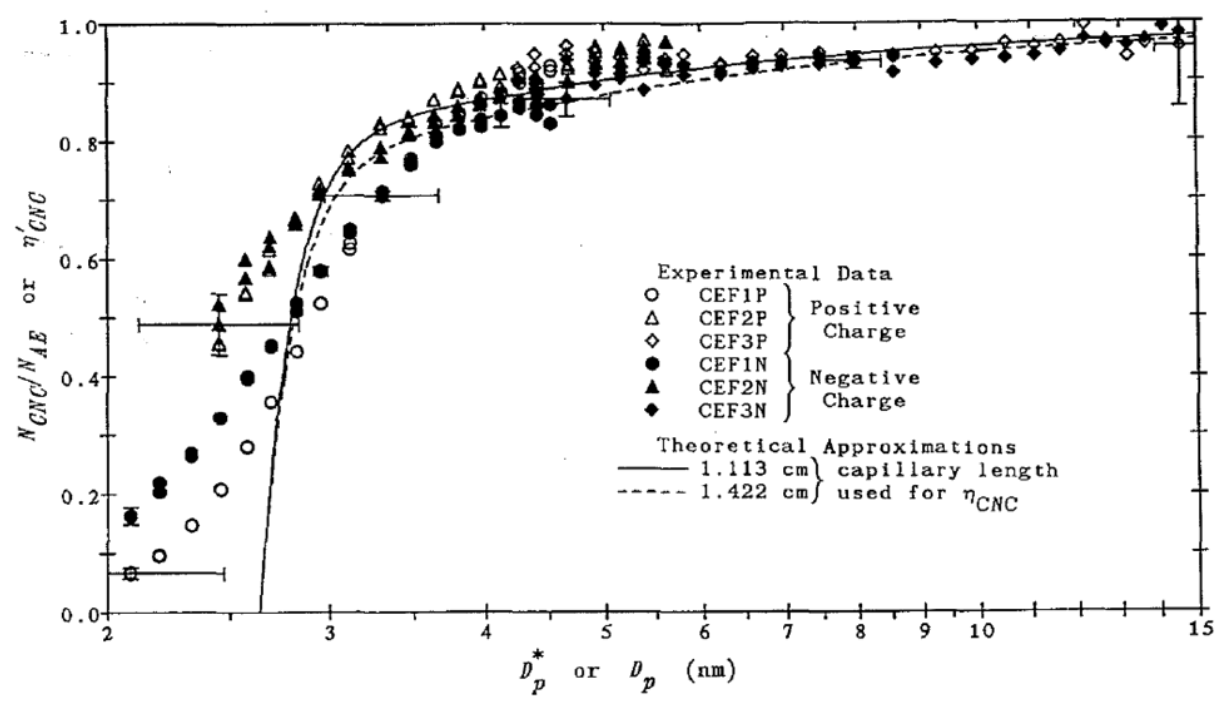

Figure 2. Detection efficiency of the ultrafine CPC prototype by Stolzenburg and McMurry (1991) (Reproduced with permission of AAAR and AS\&T).

In the same year in 1991, a calibration of the commercial TSI 3025A was published by Kesten et al. (1991). The first modification of the 3025A was also published in 1991 by McDermott et al. (1991), who showed the operation of the CPC with a fluorinated liquid, optimized flow configuration and condenser design. The modification resulted in detection efficiencies closer to unity at sizes above $4 \mathrm{~nm}$ compared with the previous operation conditions, and the increased aerosol flow rate increased the counting statistics by a factor of 5 . The purpose of the increased counting statistics was indeed to enhance the particle detection probability in extremely low particle concentration environments, such as cleanrooms. Additionally, McDermott et al. (1991) showed the particle sizing capability of the modified $\mathrm{CPC}$ between 3 and $10 \mathrm{~nm}$ by scanning the condenser temperature.

Recently, two separate publications, Attoui (2018) and Barmpounis et al. (2018), report flow and temperature modifications of the TSI 3776. By increasing the flow rate in the capillary and decreasing the condenser temperature, detection efficiency up to $5 \%$ was reached for $1 \mathrm{~nm}$ ions without significant presence of homogeneous butanol droplet formation. These results suggest that there is still space for optimization in the operation conditions of the current butanol based ultrafine CPCs for maximizing the detection efficiency of the smallest particles close to $1 \mathrm{~nm}$.

\section{PHA CPC}

Marti et al. (1996) noted that the pulse height distributions measured for monodisperse particle populations using the commercial laser based optics of the TSI 3025 were irregular in shape, but replacing the laser with a white light source changed the shape of the pulse height distributions to Gaussian. Further, the initial particle size was clearly correlated with the peak pulse height (Figure 3). This discovery is the basis of particle sizing based on the PHA method. Utilizing this finding, Saros et al. (1996) modified the TSI 3020 by replacing the laser of the optics with a white light source, and Weber et al. (1998) described a data inversion methodology for analyzing pulse height distribution data. Saros et al. (1996) reported that even if the peak channel measured with a multichannel analyzer (MCA) for a fixed particle size varied with the sample flow pressure, the relative peak MCA channels between different particle sizes stayed constant in the pressure range of $0.25-1 \mathrm{bar}$. According to this study, the largest limitation of the PHA method is that the detection efficiency of the $3 \mathrm{~nm}$ particles decreased if the total concentration of the particles was larger than $4000 \mathrm{~cm}^{-3}$. This can be overcome, however, by a suitable dilution system, presuming the ultrafine particle concentrations are high enough. Furthermore, 
they state that "The sudden decrease in counting efficiency is correlated with the increase in multichannel analyzer dead time, suggesting that the limitation was a result of particle coincidence rather than vapor depletion", suggesting that this concentration limitation could be overcome also by technological developments in the CPC optics.

After the high resolution DMA technology reached the groups of Helsinki and Minnesota, the next steps were taken in the development of laminar diffusion PHA CPCs. Sipilä et al. (2008) and Sipilä et al. (2009) constructed their version of a PHA CPC from the TSI 3025A, which was operated at a supersaturation high enough to produce homogeneously formed butanol droplets. They noticed that homogeneously formed droplets grow to smaller final droplet sizes than heterogeneously formed, and these two processes can be separated in the PHA. Because of this, the instrument can be used at onset supersaturation required for homogeneous droplet formation, thus in practice activating all particles that can be activated via heterogeneous nucleation without significant homogeneous background. Sipilä and coworkers applied this technology to measure small neutral ambient clusters and presented first longterm field observations of sub-3nm particles measured by CPCs (Lehtipalo et al. 2009). They also presented an inversion method based on PHA to get size information of 1.3-5 nm particles.

Kuang (2018) reports the first DEG based PHA CPC by modifying the Palas universal fluid CPC (Baltzer et al. 2014) by operating it with DEG and implementing a PHA to the optical particle detection. The most important advance in the work of Kuang is the optimization of the optical detector gain so that the signal from the grown DEG droplets can be separated from the electric noise. This allows the detection of the DEG droplets without an additional counter CPC, which is another interesting finding. With development of an inversion routine, Kuang demonstrates the applicability of DEG based PHA CPC for sub-3 nm particle sizing experiments even down to possibly molecular sizes. As the PHA technique can work with time resolution as fast as $1 \mathrm{~s}$, the PHA DEG CPC can possibly measure sub-3 nm size distributions with $1 \mathrm{~s}$ time resolution, which is yet to be demonstrated.

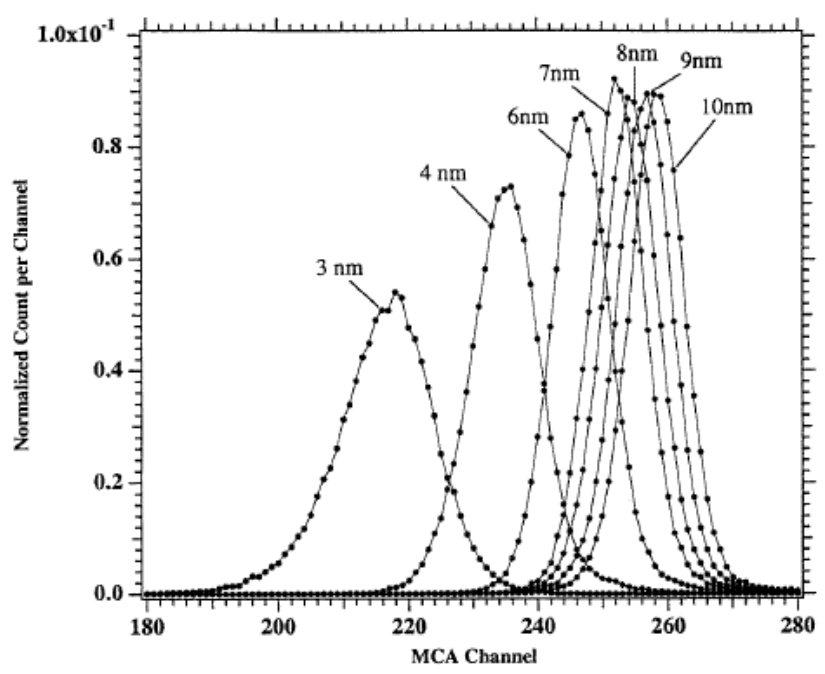

Figure 3. Pulse height distributions measured with the first PHA CPC by Marti and coworkers (Reproduced with permission of AAAR and AS\&T).

UF02 proto

The UF02 proto reported by Mordas et al. (2005), is the last CPC design following the ultrafine $\mathrm{CPC}$ of Stolzenburg. It uses similar two stage core sampling and capillary feeding of aerosols to the condenser centerline. The main difference is that the sheath flow is fed tangentially to the condenser, causing swirling flow that is further enhanced with a fan rotating around the capillary. The outlet of the condenser is conical to focus the particles to the optical detector. A cut-off of $4.5 \mathrm{~nm}$ was obtained for this proto CPC using Ag particles. Their subsequent publication presents tuning of the temperature 
difference between the saturator and the condenser $(\Delta \mathrm{T})$ for the same instrument, decreasing the cut-off down to $2 \mathrm{~nm}$ (Mordas et al. 2008b). Appreciating the limited size resolution of the $11 \mathrm{~cm}$ long Vienna DMA, they adjusted the DMA output size distribution according to the input distribution. Mordas and coworkers also show that there is a minor effect of background aerosol on the detection efficiency: particle concentration of around $3000 \mathrm{~cm}^{-3}$ lowered the detection efficiency at sizes below $2 \mathrm{~nm}$ compared to a case with no background particles.

Optimized, unsheathed butanol CPCs

After the work of Stolzenburg and McMurry (1991) and other work related to the ultrafine CPC, the next reports on the operation of laminar type CPCs toward sub-3 nm particle detection were made by Mertes et al. (1995) and Wiedensohler et al. (1997). They showed that by increasing $\Delta \mathrm{T}$ of the TSI 3010 , it is possible to detect particles down to $4 \mathrm{~nm}$ and $2.5 \mathrm{~nm}$, respectively. These results showed that even the conventional non-sheathed fine CPCs are capable of detecting the very smallest particles. The particle detection is mostly limited by sampling losses and non-uniform supersaturation field in the condenser. Later on, Kangasluoma et al. (2015a) showed that the TSI 3772 and Airmodus A20 fine CPCs are capable of even sub-1.5 nm particle detection (Figure 4), which was followed by Picard et al. (2018) by similarly boosting a TSI 3010 for airborne measurements. Such modification to the fine CPCs carry three advantages over the ultrafine design: the fine CPCs are cheaper and simpler in design, and with higher aerosol flow rates, the counting statistics will be significantly better compared to the ultrafine CPC design. The disadvantage is the larger butanol consumption because of larger flow rate and higher temperature in the saturator, and the slowly increasing detection efficiency as function of particle size in the sub-5 nm sizes. To date, no commercial design of such CPC exists for sub-3 nm sizes.

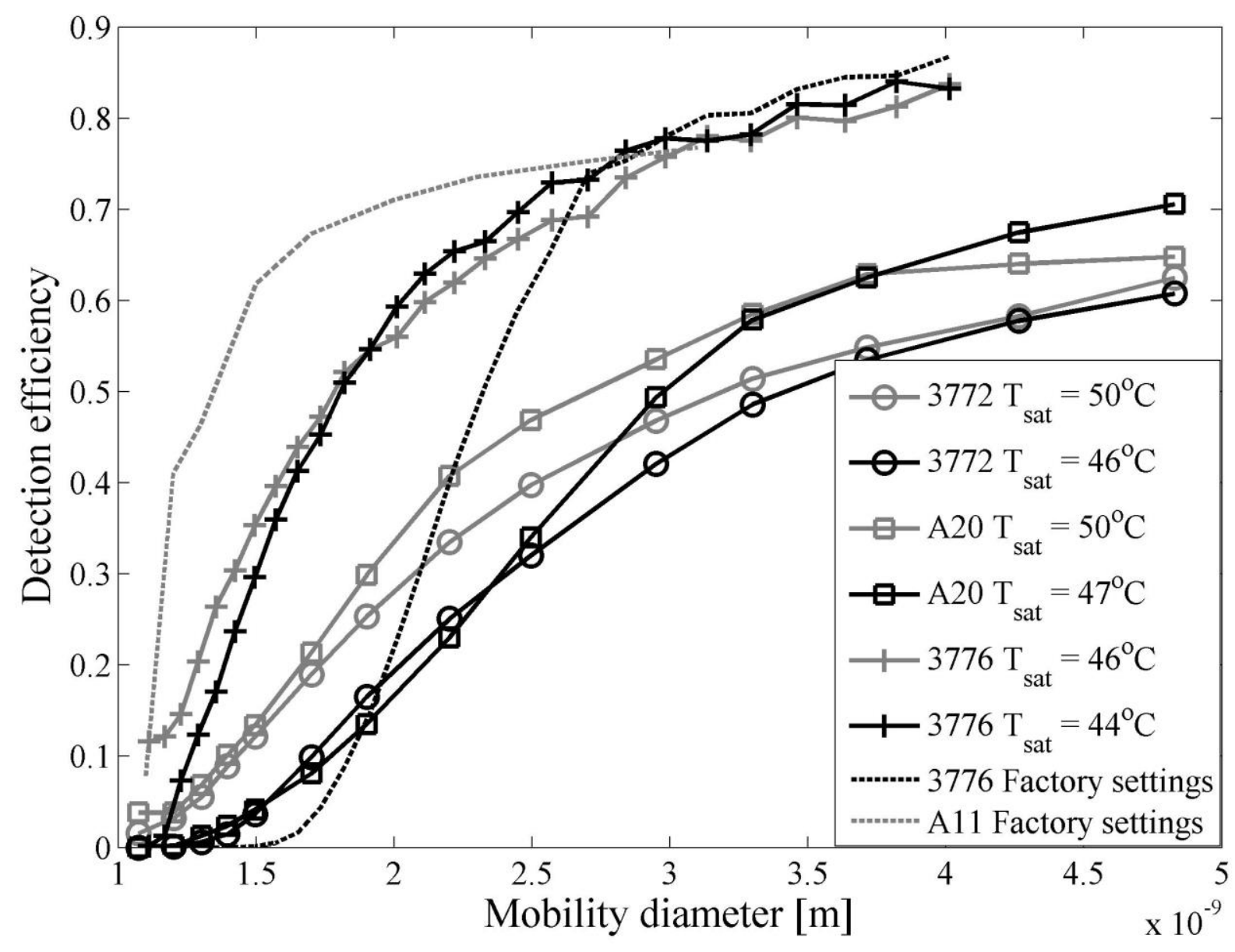


Figure 4. Detection efficiencies of the Airmodus A20 and A11, and TSI 3772 and 3776 with modified condenser and saturator temperatures. In all temperature settings the condenser is set to $10^{\circ} \mathrm{C}$ (except for the A11) (Reproduced with permission of AAAR and AS\&T).

Other butanol based CPCs

Recently, Kanomax published a fast CPC operating with butanol with a response time of $60 \mathrm{~ms}$ (defined as $3 \tau$ ) and cut-off of $2 \mathrm{~nm}$ reported by the manufacturer. In that CPC, the geometry of the condenser is planar, with sheath flow on two sides of the flow. As the residence time in the condenser is small, there is not much time to develop a profile in the flow. This leads to fast response time because only small fraction of particles are transported close to the walls where the flow velocity is the smallest. This CPC also introduces a recirculating butanol system. The CPC is part of a commercial ion mobility drift tube for particle sizing (Buckley and Hogan 2017), while no scientific reports on the CPC exist yet.

The latest CPC design has been published by Yoo et al. (2019) (laminar flow) and Kwon et al. (2019) (mixing type), who manufactured the saturator and condenser using microelectromechanical design. The saturator and condenser surfaces are full of microcapillaries that are used to bring the working fluid from the liquid reservoir to the saturator via capillary action. This surface makes it possible to construct a more complex saturator flow path and to use lighter materials, thereby reducing the size and weight of the CPC. The cut-off of both CPCs were around $13 \mathrm{~nm}$. In the future new fabrication techniques might allow further miniaturization of sub-3nm CPCs.

\section{Water CPCs}

Two-stage water CPCs

A major conceptual improvement in the laminar flow diffusion CPCs was the invention of water based CPCs (Hering and Stolzenburg 2005), of which the first one was designed and reported by Hering et al. (2005). It exploits the higher diffusivity of water relative to heat in air by first cooling down the sample flow in a conditioner and subsequently heating it up in a growth tube with water-wetted walls. In contrast to the butanol CPCs with usually horizontal saturator and vertical condenser, the first water $\mathrm{CPC}$ design is a continuous porous wick spanning from the inlet through conditioner and growth tube to the optics. The conditioner and growth tube are only separated by the different wick temperature. This design was commercialized as the TSI model 3785 fine particle counter with cut-off diameter somewhere between 4 to $30 \mathrm{~nm}$ depending on the test aerosol composition: For salts, sucrose and ambient particles the cut-off was in the range of 3-5 nm, for oleic acid $8 \mathrm{~nm}$, and for contaminated and pure oil droplets starting from $7 \mathrm{~nm}$ up to anywhere close to $50 \mathrm{~nm}$ and larger (Hering et al. 2005; Liu et al. 2006; Petäjä et al. 2006). Soon after, an ultrafine design of the water CPC was commercialized by TSI by adding a sheath flow design to the inlet of the conditioner with both aerosol and sheath flow rate of $0.3 \mathrm{~L} \mathrm{~min}^{-1}$ (Figure 5). The design of the ultrafine water CPC has been characterized by Liu et al. (2006), Iida et al. (2008), Mordas et al. (2008a), and Kupc et al. (2013a), and depending on the $\Delta \mathrm{T}$ and particle composition, the cut-off was pushed even down to $2.25 \mathrm{~nm}$. Experiments with oil droplets, on the other hand, exhibited cut-off starting from $15 \mathrm{~nm}$ up to larger than $50 \mathrm{~nm}$ depending on the oil purity. 


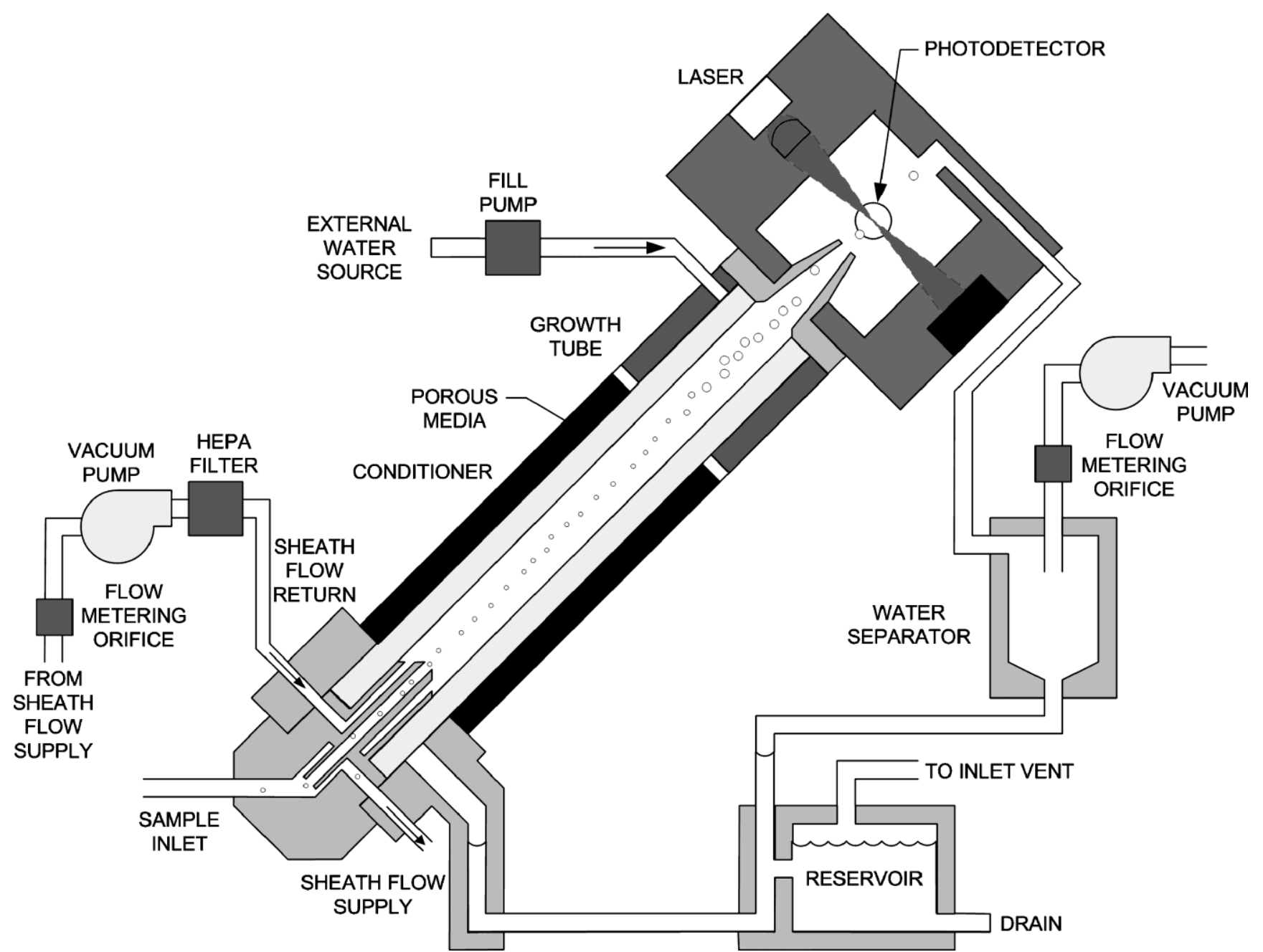

Figure 5. Design of the ultrafine water CPC reported by Iida et al. 2008 (Reproduced with permission of AAAR and AS\&T).

Three-stage water CPCs

More recently, Hering and her coworkers have continued the development of the laminar flow water CPC technology by implementing a third stage to the continuous tube between the growth tube and optics, moderating the flow temperature back to around $20^{\circ} \mathrm{C}$ (Hering et al. 2017; Hering et al. 2014). This advance has two major consequences: a supersaturation peak can be created with high $\Delta \mathrm{T}$ between the conditioner and initiator (high temperature stage in the middle), while the supersaturation will be brought down fast by the moderator, allowing the use of very high supersaturation and activation of $1 \mathrm{~nm}$ particles without homogeneous water droplet formation (Figure 6). This feature is utilized in the versatile water CPC, commercialized by TSI as the model 3789. This CPC can be operated at the extreme temperatures of water, conditioner at $1{ }^{\circ} \mathrm{C}$ and initiator at $99^{\circ} \mathrm{C}$, leading to high detection efficiencies even at $1 \mathrm{~nm}$ mobility diameter. Water is directly injected to the middle stage to handle the rapid evaporation. 

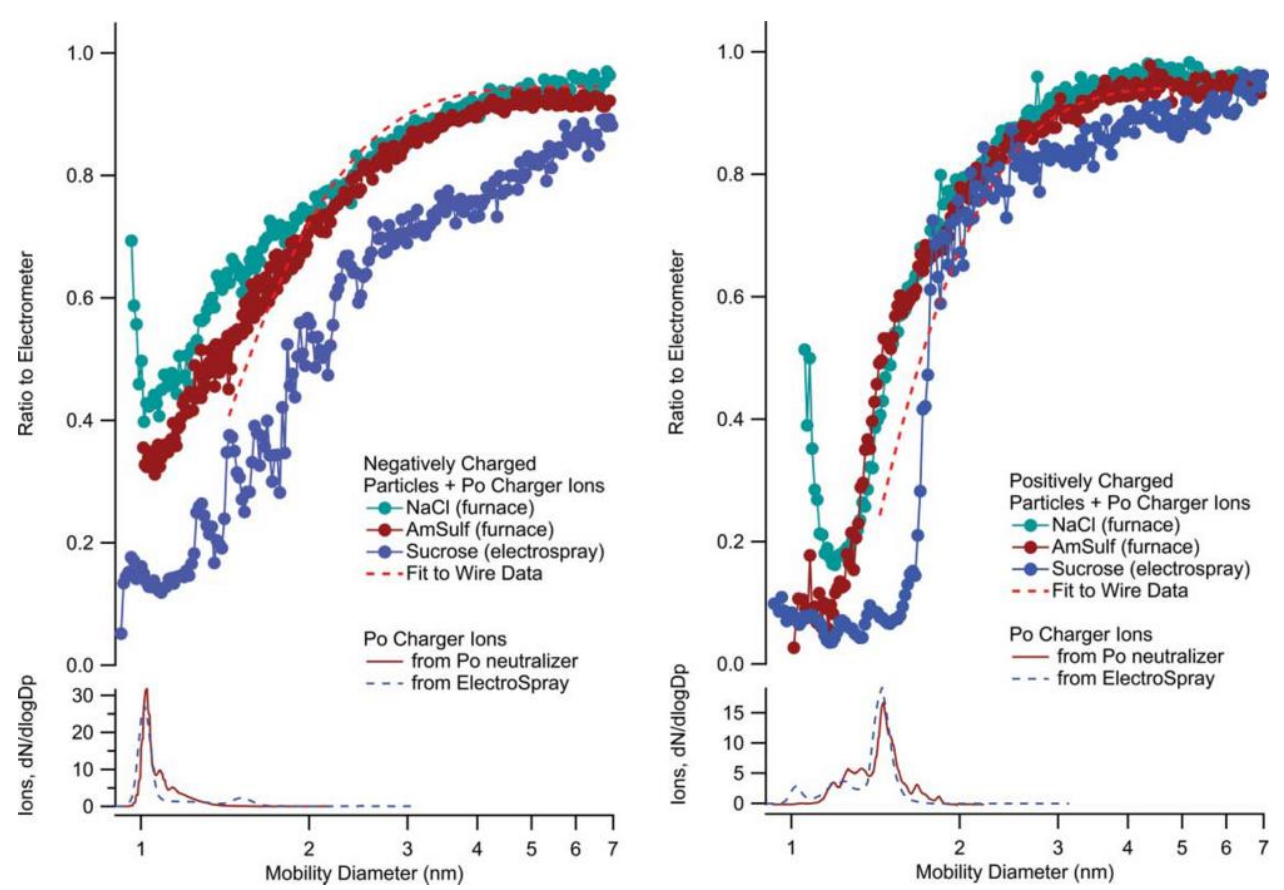

Figure 6. Calibration of the vWCPC reported by Hering et al. (2017) (Reproduced with permission of AAAR and AS\&T).

The second, even more significant impact is that the water vapor concentration in the moderator is decreased close to the level of the water concentration at the inlet. As the wetted wick is continuous, the water condensed to the moderator walls flows back to the initiator due to capillary force. Water that is used to grow the particles will be collected from the sample flow in the cold conditioner, to where water condenses and similarly flows to the initiator. This tremendous design has been shown to be functional for several weeks using only the water vapor of the atmosphere without additional water fill bottle and in any CPC alignment (Hering et al. 2018). This is also from where the acronym "Magic" originates (Moderated Aerosol Growth with Internal water Cycling). In very dry or cold environments, the Magic CPC still requires additional humidifier upstream of the CPC inlet. Such design is the first step toward long term unattended monitoring of particle concentrations in places that hard to reach for maintenance.

\section{Other water-based CPCs}

Three other groups have followed the idea of using water as the CPC working fluid, while, slightly surprisingly, using similar heated saturator and cooled condenser as in the butanol CPCs. Romay et al. (2016) report a condenser design, in which the aerosol is fed tangentially to the partly conical cylinder, causing cyclonic flow spinning toward the condenser exit. This CPC design was commercialized as the MSP CPC models 1110 and 1120, the production of which is now already discontinued. With the saturator at $35^{\circ} \mathrm{C}$ and condenser at $4^{\circ} \mathrm{C}$ the cut-off for $\mathrm{NaCl}$ was shown to be $3.9 \mathrm{~nm}$.

Hwang and Ahn (2017) present the first miniaturized water CPC with dimensions of about $80 \times 190 \mathrm{~mm}$ and weight of $1 \mathrm{~kg}$. It follows the standard butanol CPC operation scheme with temperatures of $64^{\circ} \mathrm{C}$ and $3{ }^{\circ} \mathrm{C}$ for the saturator and condenser respectively. A cut-off of $3 \mathrm{~nm}$ is reported for this CPC for zinc particles. Enmont have commercialized a miniature water CPC with models PUFP100, PUFP110 and PUFP200, while detailed publications on the CPC design was not found in the literature. Asbach et al. (2017) has published a concentration response comparison of the PUFP100 against the TSI 3776 with reasonable agreement for $\mathrm{NaCl}$ and carbon particles, and strong underestimation for oil droplets. The cut-off performance characterization of the Enmont CPC is missing from the literature. 
The main achievements of these two CPCs is miniaturization compared to standard CPCs, which is a step toward new applications, such as personal sampling or deployment in unmanned aerial vehicles.

\section{Discovery of DEG}

The group of Minneapolis began their second wave of sub-3 nm CPC development with the work of Iida et al. (2009). They studied theoretically hundreds of different liquids in the TSI 3025A condenser, confining the $\Delta \mathrm{T}$ so that the homogeneous droplet formation rate was below $1 \mathrm{~min}^{-1}$. Their theoretical analysis showed that of the nonhazardous liquids, diethylene glycol (DEG) can activate the smallest particles because of the low vapor pressure and high surface tension. The prediction was in sound agreement with the experiments in the sense that DEG activates the smallest particles of the tested liquids. However, their model predicted cut-off of about $1.85 \mathrm{~nm}$, which is in disagreement with the experimentally determined detection of almost unity at $1 \mathrm{~nm}$ mobility diameter for sodium chloride (Figure 7). While the result of $100 \%$ activation efficiency at $1 \mathrm{~nm}$ is remarkable, it was only for particles of one type chemical composition. Thus, we are left with the problem that how to deal with the activation efficiency if the particle composition is unknown? Another finding in the same report is that the CPC activation efficiency is dependent on the sample flow relative humidity for ethylene and propylene glycol. The experiments of Iida et al. were conducted using a modified TSI 3025A, for which the main modification was that they removed the optical counter, and placed another TSI fine CPC instead to count the grown droplets. Because of the low vapor pressure of DEG and other tested liquids, the droplets do not grow inside the 3025A to optically detectable sizes, thus a subsequent CPC is required to further grow and count the particles. The two stage system has been already suggested by Seto et al. (1997). The application of DEG for sub-3 nm CPCs was a groundbreaking discovery, and the liquid is utilized in most current sub- $3 \mathrm{~nm}$ particle measurements. 


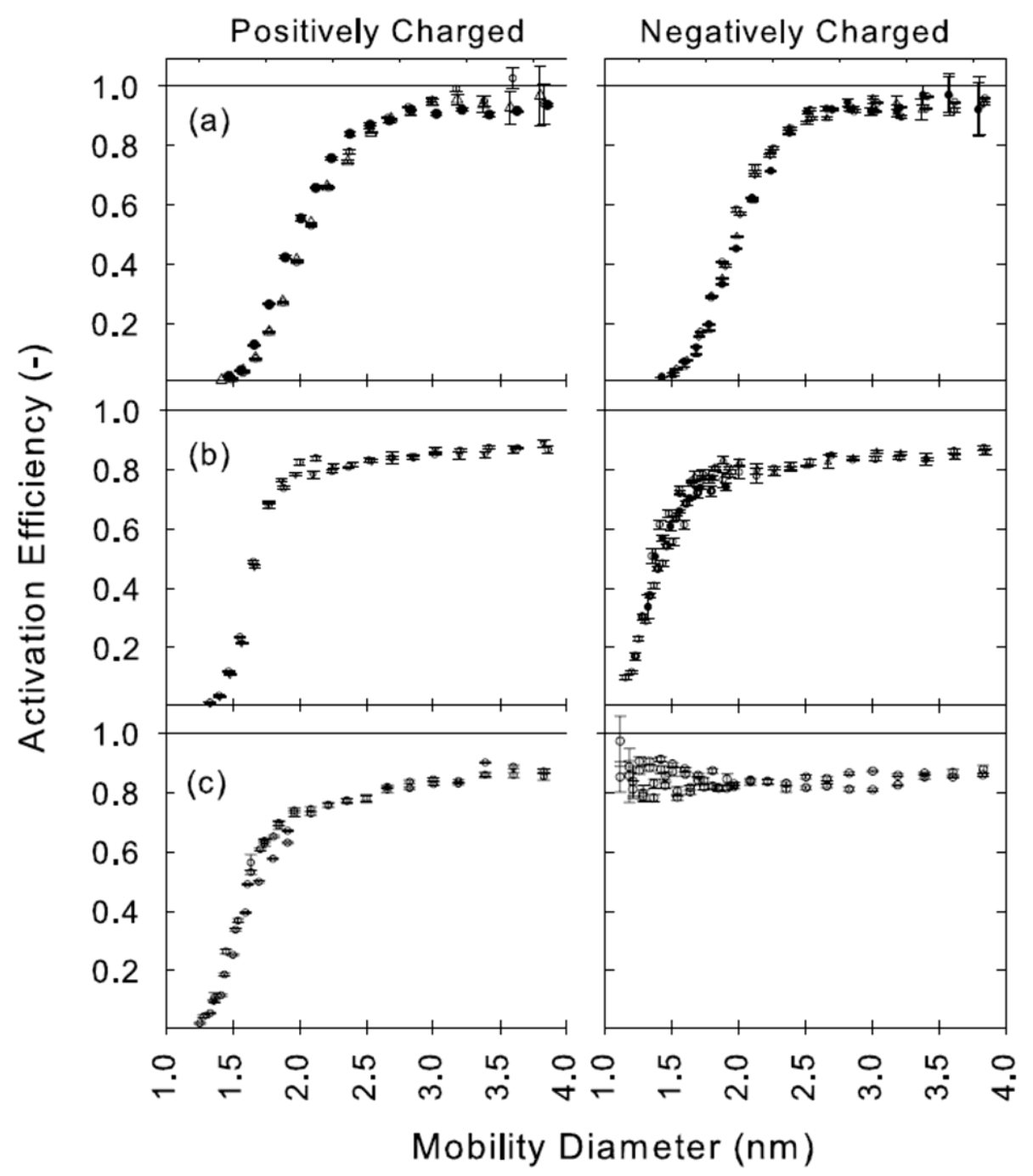

Figure 7. Measured detection efficiency curves for diethylene glycol for a) silver, b) ammonium sulfate, c) sodium chloride with the modified 3025A by Iida et al. (2009) (Reproduced with permission of AAAR and AS\&T).

\section{DEG based laminar flow CPCs}

Based on the modifications of Iida et al. (2009) to the TSI 3025A, Jiang et al. (2011b) modified a similar DEG CPC to be a detector in a particle sizing system to observe atmospheric new particle formation (Jiang et al. 2011c). Their DEG SMPS is the first SMPS type instrument modified for sub-3 $\mathrm{nm}$ particle detection. The DEG SMPS was later improved by replacing the TSI 3085 nanoDMA used in Jiang et al. (2011c) with a newly developed mini-cyDMA (Cai et al. 2017a; Cai et al. 2019). In the improved DEG SMPS, the TSI 3776 was modified to run DEG as the working fluid. Further, thanks to the calibration setup allowing the separation of large molecules organic molecules, Jiang and coworkers report that the detection efficiency is strongly dependent on chemical composition of the test particles: DEG activates certain hydrocarbon species poorly compared to sodium chloride. Some years later, Kangasluoma et al. (2018) reported construction of another sub-3 nm DMPS system, but based on the Half-mini type DMA (Fernandéz de la Mora 2017), with a sampling inlet optimized for sub-3 nm particles (Fu et al. 2019; Kangasluoma et al. 2016b) and a commercial mixing type CPC. Their results confirm in the field studies what others found in the laboratory: DEG does not activate organic species well. Thus, the smallest detected particles with that instrument were around $3 \mathrm{~nm}$ in atmospheric experiments in boreal forest. Further, they compare the counting statistics of the optimized DMPS and 
a long term monitoring DMPS, finding that the counting statistics related uncertainties are 50\% smaller for the new instrument. A commercial $1 \mathrm{~nm}$ SMPS based on Jiang et al. (2011b) was released around 2015 by TSI. In this commercial instrument, the TSI 3086 DMA (Stolzenburg et al. 2018) is used. To date, no scientific literature exists on the commercial instrument.

With similar modifications to the 3025A as described previously by Iida and coworkers, Kuang et al. (2012b) boosted their DEG CPC further by modifying the flow configuration by changing the aerosol and condenser flow rates. Their findings showed that increasing the $\Delta \mathrm{T}$ and aerosol flow rate in the condenser improved both detection efficiencies and counting statistics. Wimmer et al. (2013) modified two TSI 3025As in similar fashion as Jiang et al. (2011b) and Kuang et al. (2012b), and verified the instruments together with the two first commercial mixing type CPCs by Airmodus. Wimmer et al. (2015) further studied the response of the DEG CPCs to measure very cold aerosol samples, finding around 1-2 nm increase in the cut-off for aerosol samples at temperatures of $207 \mathrm{~K}-246 \mathrm{~K}$ compared to the laboratory experiment at $293 \mathrm{~K}$. All these modified DEG CPCs were shown to have the cut-off below $2 \mathrm{~nm}$ for negative sodium chloride particles, and for some other substances, without the presence of homogeneously formed droplets. Based on these modifications on the TSI 3025A or 3776, TSI commercialized the DEG CPC as the TSI Nano Enhancer 3777 (Kangasluoma et al. 2017), and very soon after Nano Enhancer 3757.

\section{Mixing type CPCs}

\section{Yale PSMs}

The first time mixing CPCs were shown to be capable of detecting sub-3 $\mathrm{nm}$ particles was a result from collaboration by Okuyama and Fernandéz de la Mora, who combined the particle size magnifier (PSM) and the new high resolution DMAs to the same experimental setup. Seto et al. (1997) reported critical supersaturations of dibutyl phthalate (DBP, toxic and carcinogenic liquid) required for growing strictly monomobile ions close to $1 \mathrm{~nm}$ in size. Their "short DMA," a shortened version of the Reischl design, was capable of separating and selecting individual ions from the mobility spectrum. This allowed them to measure a critical supersaturation value for each individual ionic species.

The experimental setup (Figure 8) of Seto and coworkers is the first one to combine a high resolution DMA with a CPC. This instrumental combination is a significant advance in conducting experiments to understand the possibilities and limitations of condensation based particle counting. In their PSM, DBP is evaporated from a heated silica gel bed to into a gas stream, which is delivered to a turbulent mixer where it is blended with the sampled aerosol. The PSM mixer includes four small holes, from which the cooled aerosol flow is injected and mixed with the saturated flow. Downstream of the mixing zone is a temperature controlled section to condition the flow temperature close to the mixing zone temperature. The supersaturation of DBP was controlled by varying the temperature of the saturator. Because of the low vapor pressure of DBP, the droplets do not grow to optically visible sizes. Seto and coworkers solve this challenge by introducing a second CPC (booster) to count the grown droplets. In this configuration the PSM operates only as a particle magnifier prior to conventional CPC, from where the acronym PSM originates (initially from Okuyama et al. (1984)). 


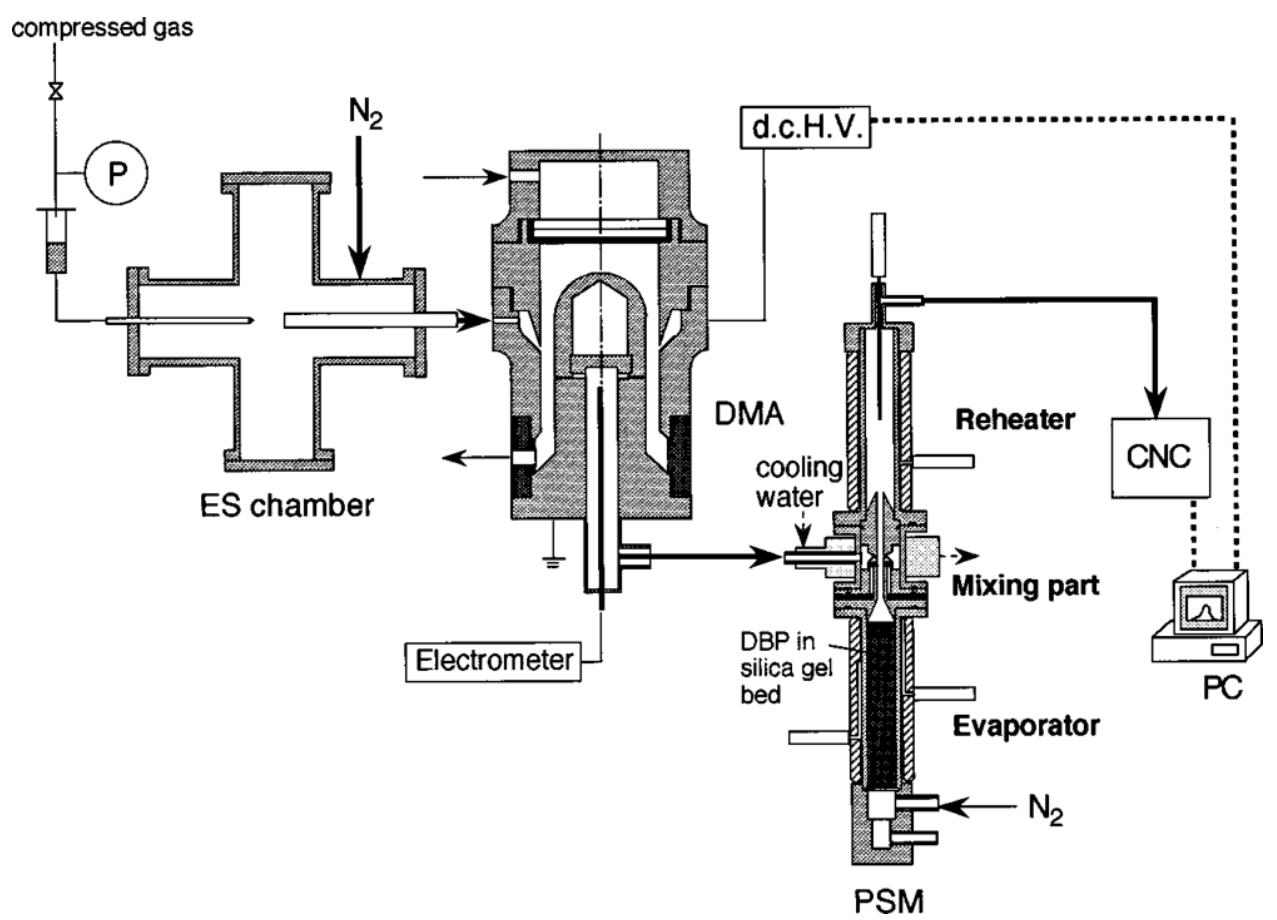

Figure 8. Experimental setup of Seto et al. (1997) (Seto, T., Okuyama, K., de Juan, L., Fernandéz de la Mora, J. (1997). Condensation of supersaturated vapors on monovalent and divalent ions of varying size. Journal of Physical Chemistry 107:1576-1585).

Gamero-Castano and Fernandéz de la Mora (2000; 2002) improved the previous PSM design by including a reheater between the saturator and the mixing section, which minimized the DBP loss before the mixing section and, therefore, allowing more accurate estimation of the fluid supersaturation in the mixing zone. The reheater also prevented the DBP from nucleating homogeneously before the mixing section, further reducing vapor losses prior to the mixing section. With this improvement, the supersaturation can be scanned more rapidly by varying the flow rate through the saturator instead of varying the temperature of the saturator. Further, the number of aerosol feeding inlets in the mixing piece was reduced from four to two to increase Peclet number and enhance mixing. The experiments of Gamero-Castano showed that when the test ions are small enough, the activation probability does not depend on the ion size (mobility) anymore. This feature of heterogeneous nucleation has been predicted theoretically later (Fernandéz de la Mora 2011), but to date has not been confirmed by other experimental researchers. Gamero-Castano and Fernandéz de la Mora also compared their results to the Kelvin and Thomson's equation using the mixing type CPC, showing reasonably good agreement.

The most recent PSM design published by the Yale group is described by Sgro and Fernandéz de la Mora (2004), in which the new T-shaped aerosol injection design improved the penetration of the smallest particles. It is the simplest version of the PSMs published so far. This PSM was found to be capable of activating $1.7 \mathrm{~nm}$ ions at $100 \%$ efficiency using DBP, and also growing them large enough for direct optical detection as opposed to the previous DBP based PSMs. This publication also includes an interesting appendix on the previously tested PSM designs.

The construction and characterization of the laboratory PSMs and high resolution DMAs by Fernandéz de la Mora and his collaborators, and their fundamental research on ion-induced nucleation, set the stage for improving the CPC technology for sub-3 nm particle detection and calibrations that are applicable to atmospheric and other applied measurements. As already noted, the use of high resolution DMAs by the Helsinki and Minneapolis groups occurred several years after they were first described by Fernandez de la Mora and coworkers.

\section{Other PSMs}


Kim et al. (2002) and Kim et al. (2003) present another two versions of a PSM, which are able to detect $3 \mathrm{~nm}$ particles. They introduce ethylene glycol as the working fluid, as it is odorless and harmless, while good in activating sub-3 nm particles. Kim's PSM of 2002 is a commercial mixing type CPC (MTCPC) by Kanomax. The mixing piece includes four aerosol inlets to mix with the saturated flow, which possibly leads to some aerosol losses and not $100 \%$ detection efficiency at $3 \mathrm{~nm}$. New in the work of Kim et al. (2002) was the extensive probing of the PSM operation below normal atmospheric pressure. The performance was found not to change dramatically at pressures down to 200 torr (26.7 $\mathrm{kPa}$ ), allowing the use of PSM at high altitudes. Another interesting note from this work is that the counting efficiency of the PSM is almost equal when the detector is a CPC or an optical counter. It suggests that most particles grow to optical sizes, and the extra CPC is unnecessary. This is contradicting with e.g. the current commercial designs of the DEG based CPCs. The PSM of 2003 by Kim et al. is a laboratory prototype, in which the mixing section was simplified so that it included only one aerosol inlet based on the PSM design of Sgro and Fernandéz de la Mora (2004), i.e. it had a shape of a T. Another difference in the design was that the condenser was conical. The second PSM of Kim et al. was characterized down to sub-2 $\mathrm{nm}$ particles, with remarks on ion induced nucleation. Ethylene glycol was found to prefer nucleation on negative ions.

Four more independently developed mixing CPCs are by Mavliev and Wang (2000) and Mavliev (2002), which operated with DBP as working fluid and were capable of activating $3 \mathrm{~nm}$ particles. Ito et al. (2011) published a PSM, which was operated with ethylene glycol as working fluid, and Kim et al. (2015) studied the temperature dependence of heterogeneous nucleation with their PSM operated with DEG as working fluid. Wang et al. (2002) developed a butanol based fast response time mixing CPC for rapid SMPS measurements. They showed that even time resolution of one second was possible for an SMPS if the detector was the fast CPC. This CPC model is commercialized as the Brechtel MCPC.

\section{Commercial PSM}

To date, the last commercialized version of the sub-3 nm PSMs was published by Vanhanen et al. (2011) (Figure 8). Their DEG-based PSM design is close to the one of Sgro and Fernandéz de la Mora (2004), consisting of a simple T-shaped mixing piece with one aerosol inlet in the mixing piece. Indeed, the largest advance in the engineering of this PSM is that it is field deployable, and it includes automated supersaturation scan via simultaneous scanning of the flows passing through the saturator and exiting the PSM. Another advance of this PSM is that the turbulent mixer is fabricated from electrically conductive plastic, which insulates the hot and cold parts. When operated with the normal factory settings for temperatures, the maximum supersaturation in this PSM takes place in the growth tube downstream of the mixing section. In some cases, this has led to non-monotonic increase in the detected particle concentration with increasing supersaturation due to two separate regions of almost equal supersaturation (Kangasluoma et al. 2016b). The PSM was commercialized by Airmodus as model A09 and later on A10. Airmodus A11 is then A10 combined to their A20 butanol CPC. The impact of this PSM to the ultrafine particle measurements is comparable to the series of ultrafine CPCs by TSI, as through commercialization the aerosol community has now access to the 1-3 nm particle size distribution measurements (e.g. Kontkanen et al. 2017) (Figures 9 and 10). Similar to water, the detection efficiency of DEG is strongly dependent on the particle chemical composition, and much of the subsequent efforts in understanding the applicability of this PSM to atmospheric measurements has been to understand its response to various particle compositions. These are discussed more thoroughly in the calibration section. 


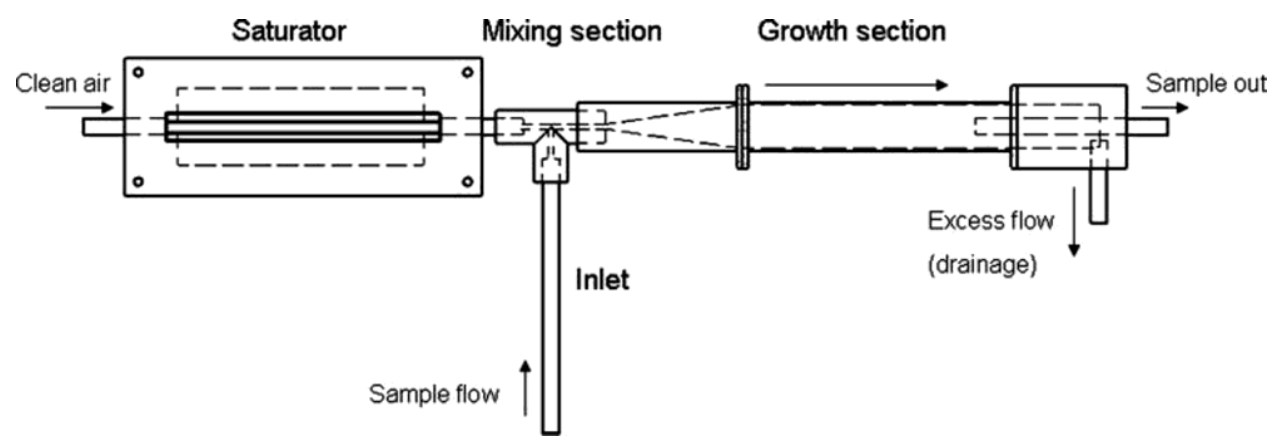

Figure 9. PSM design of Airmodus (Vanhanen et al. 2011) (Reproduced with permission of AAAR and AS\&T).
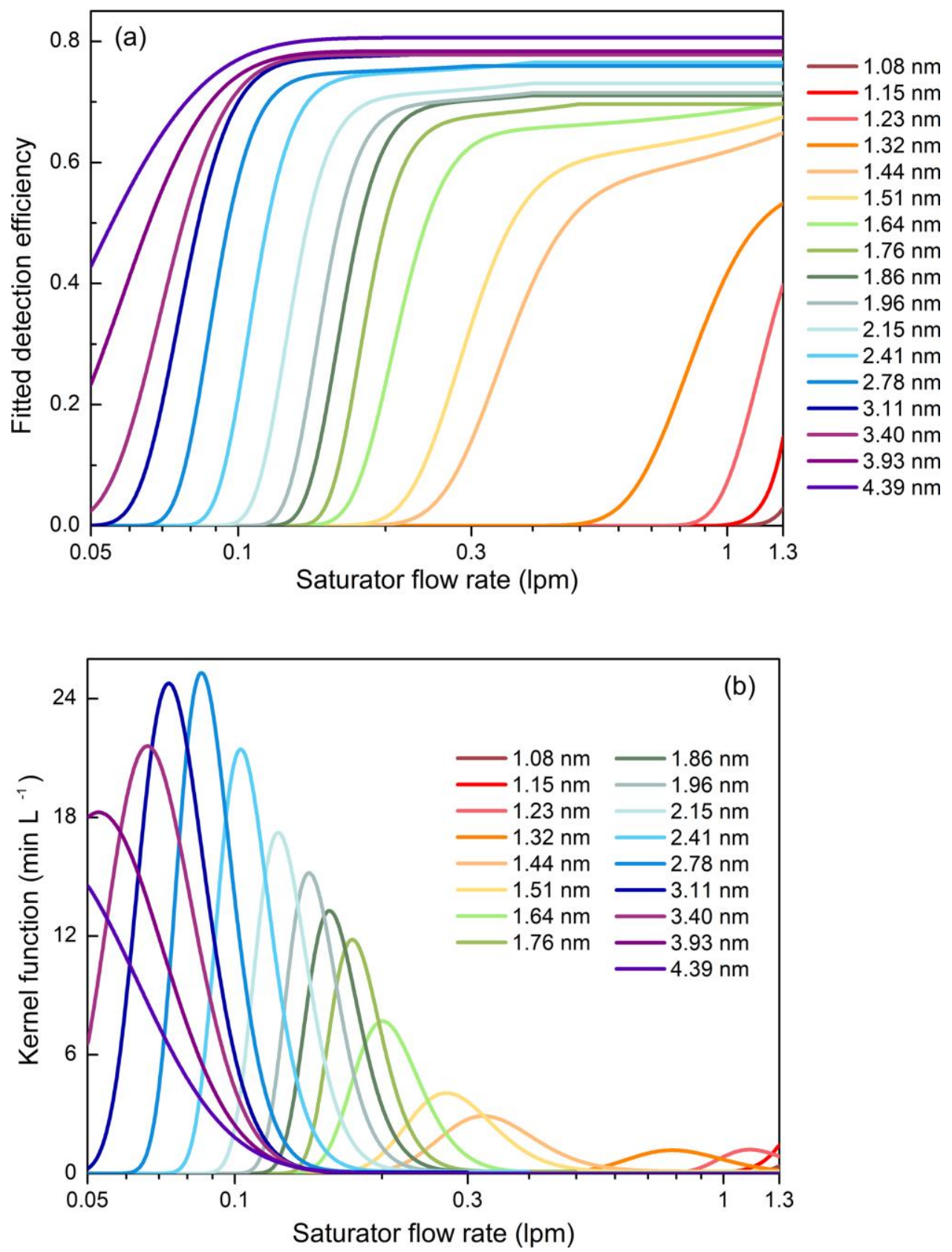

Figure 10. Typical calibration of the Airmodus PSM and the kernel functions (Cai et al. 2018) (Reprinted with permission under Creative Commons Attribution 4.0 License). 


\section{Expansion type CPCs}

An expansion CPC built by the Vienna group, the size analyzing nuclei counter (SANC), utilizes sophisticated optical detection published by Wagner (1985). Particles are brought to an expansion chamber through a humidifier that saturates the sample flow with the working fluid. By rapidly expanding the chamber the working fluid becomes supersaturated uniformly in the chamber. The supersaturation is defined from the expansion ratio and temperature of the sample, while the absolute particle concentration is obtained from the time dependent intensity of the light scattered by the particles, and is an absolute concentration measurement. Furthermore, it allows separation of homogeneous and heterogeneous nucleation. The SANC is more an instrument for heterogeneous nucleation research due its large size, than a CPC for particle concentration measurements. Starting from the year 2008, the Vienna group has published a variety of notable experimental studies on heterogeneous nucleation. Winkler et al. (2008b) showed that expansion CPCs can be made sensitive to $1.4 \mathrm{~nm}$ particles without the presence of homogeneous nucleation when operated with propanol. They further used the SANC to show that propanol prefers the activation of negative ions over positive ions at constant mobility diameter, for the first time taking into account also the size selected neutral particles with sufficient experimental accuracy (Winkler et al. 2008a). The Vienna group has also published articles homogeneous nucleation (Strey et al. 1986; Strey et al. 1994), factors that influence the critical cluster size using clean monomobile ions (Winkler et al. 2012), testing the heterogeneous nucleation theory using the nucleation theorem and activation curves from monomobile ions (Tauber et al. 2018), and building of the portable SANC (Figure 11) (Pinterich et al. 2016) and other publications on heterogeneous nucleation (Kupc et al. 2013b; Winkler et al. 2011). One of their latest reports (Tauber et al. 2019b) shows quantitative intercomparison between the SANC and a TSI 3776 detection efficiency based on the quantified supersaturation inside the SANC chamber and also, similar to findings of Barmpounis et al. (2018), that the detection efficiency of a butanol CPC is increased with decreased condenser temperature. In another recent report Tauber et al. (2019a) study in more detail the effect of nucleation temperature, particle charge and sample relative humidity on heterogeneous nucleation of $\mathrm{NaCl}$ and $\mathrm{Ag}$ seeds in the size range of 1-11 nm. The cut-off for the TSI 3776 was found to be reduced when the CPC condenser was operated at lower temperatures but constant $\Delta \mathrm{T}$. Increasing relative humidity was shown to significantly reduce the cut-off of the TSI 3776. 


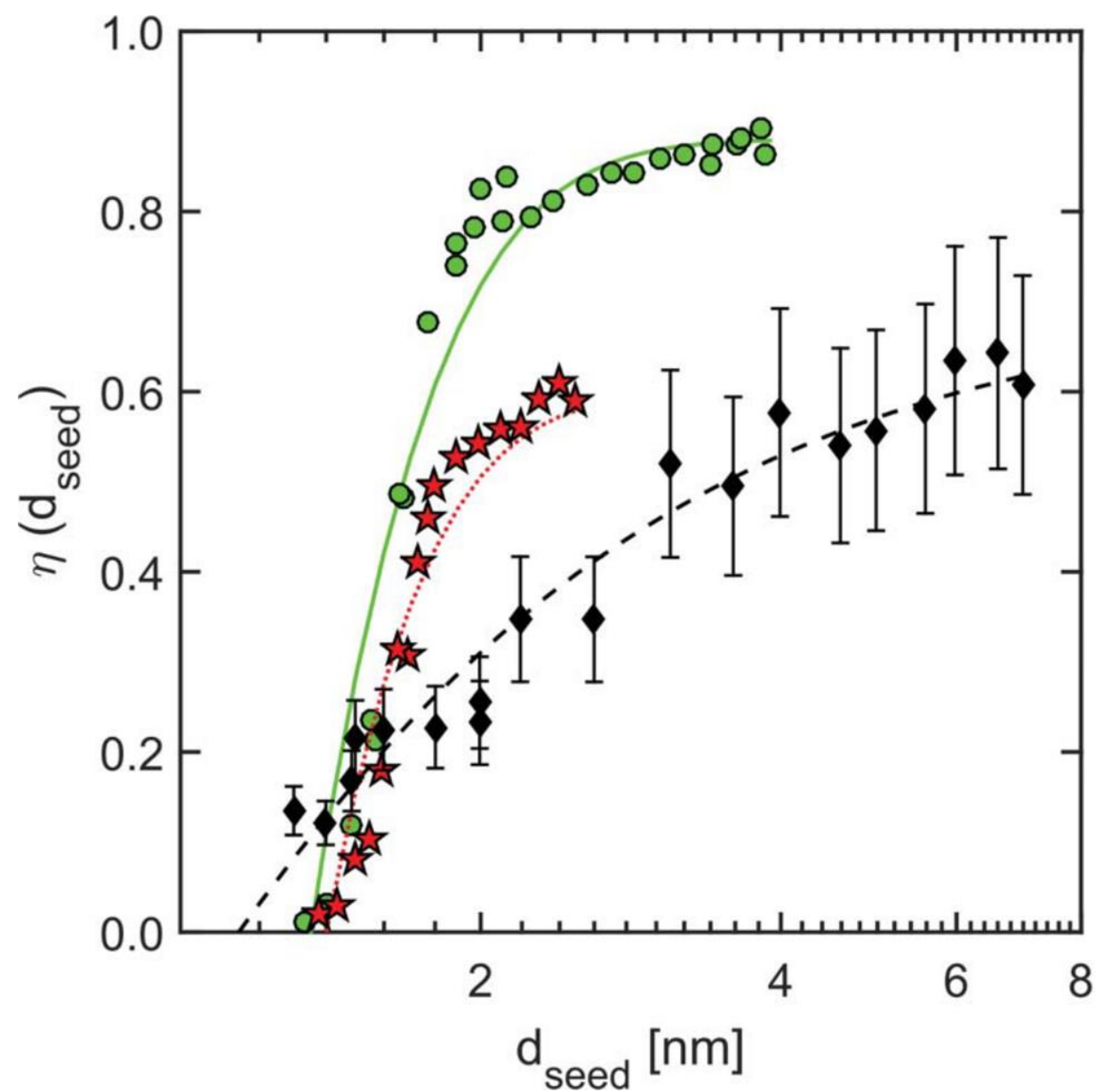

Figure 11. Size dependent CPC counting efficiencies of positively charged ammonium sulfate particles. Diamonds (black) refer to vSANC counting efficiency data. Circles (green) and stars (red) are activation efficiencies of an ultrafine CPC (modified TSI Model 3025; Iida et al. 2009) and a nCNC (Airmodus Model A11), respectively, both using diethylene glycol as working fluid (Pinterich et al. 2016) (Reproduced with permission of AAAR and AS\&T).

In 2005 an expansion CPC was published, which was the first time when the detection efficiency of an expansion CPC was characterized down to $3 \mathrm{~nm}$ by Kurten et al. (2005). Their CPC utilized an optical detector based on Mie scattering developed by Wagner (1985), which follows the size evolution of the growing droplets with a high time resolution. Kurten and coworkers compared their expansion CPC against the TSI 3025A, finding good agreement down to $3 \mathrm{~nm}$. Later the same instrument was used by Sipilä (2008) to detect sub-3nm clusters in both field and laboratory using either water or butanol as condensing liquid.

\section{Calibrations}

In this section we review past efforts in sub-3 nm CPC calibrations, starting again from the work of Stolzenburg and McMurry (1991). The following parameters are discussed: DMA output particle distribution, sample flow pressure, CPC response time and cut-off. Lastly, in the next section we look at the currently used cluster production methods in CPC calibrations.

Pushing the cut-off below $3 \mathrm{~nm}$ was first achieved at Yale University by the group of Fernandéz de la Mora with mixing type CPCs in around 1997 after they developed the first moderate/high resolution DMAs (Rosell-Llompart et al. 1996) capable for selecting monodisperse ions and clusters from electrosprayed samples. Later, after acquiring one of the Herrmann type DMAs (Kangasluoma et al. 2016a), the groups of Minnesota and Helsinki were able to push the cut-off of 
laminar diffusion CPCs below $3 \mathrm{~nm}$ (Jiang et al. 2011b; Sipilä et al. 2009). Only Mordas and coworkers in their publications on year 2008 present cut-offs below $3 \mathrm{~nm}$ using a "conventional" DMA. DMA resolution here is defined $\mathrm{Z} / \Delta \mathrm{Z}$ (Flagan 1999), often measured for the tetraheptylammonium ion at inverse mobility of $1.03 \mathrm{Vs} \mathrm{cm}^{-3}$, and high resolution for a DMA is around 20 or more. Such resolution is high enough to separate monodisperse ion with known composition from the mobility spectrum, and when combined to suitable particle generators and CPC calibration setup, gives insights into the vaporliquid interactions, which play crucial role in determining the CPC cut-off, as discussed below.

\section{DMA output distribution}

The study of Stolzenburg and McMurry (1991) includes valuable discussion on the importance of proper particle production setup in the calibrations. At sub-3 nm size range, diffusion broadening of the DMA transfer function is significant, and therefore the particle size distribution at the DMA inlet can skew the output particle distribution significantly (Stolzenburg and McMurry 2008). The lower the DMA resolution, the more significant this skewing will be. Using a low resolution DMA in a sub-3 nm CPC calibration leads to overestimation or underestimation of the CPC cut-off, depending on whether the input distribution mode diameter is larger or smaller than the DMA set point diameter. Stolzenburg and McMurry (1991) demonstrate this effect by performing three sets of calibrations with different DMA input particle distributions, which result in cut-offs of around 2.5-3 nm. We perform simple simulation of a CPC calibration by simulating a DMA transfer function (according to Stolzenburg and McMurry 2008) of the TSI long DMA, TSI nanoDMA at aerosol-to-sheath flow ratio of 0.1, and the Halfmini DMA (long/fat, Fernandéz de la Mora and Kozlowski 2013) at flow ratio of 0.1 and 0.02 (Figure 12), leading to resolutions of $0.85,3.8,6.7$ and 20.1 at $1.46 \mathrm{~nm}$, respectively. Use of a low resolution DMA skews the DMA output particle distribution, leading to skewed detection efficiency $(\eta)$ curve. The results suggest that a resolution of around 10 is sufficient for avoiding such calibration artifacts. Similar conclusion is reached by Cai et al. (2019), who suggests DMA resolution of around 69 is sufficient for avoiding the largest sizing uncertainties in atmospheric particle sampling. Of the current DMAs, of which resolution has been characterized with the tetraheptylammonium positive ion, the Half-mini (both $\mathrm{p}$ and m models), Herrmann and planar DMA can easily reach such resolution due to ability to handle high sheath flow rates (Amo-Gonzalez and Perez 2018; Fernandéz de la Mora 2017; Kangasluoma et al. 2016a; Santos et al. 2009), while the TSI nanoDMA (models 3085 and 3086), Grimm S-DMA, nano-radial DMA and the mini-cyDMA reach resolution of around 4-6 as reported currently (Brunelli et al. 2009; Cai et al. 2017a; Jiang et al. 2011a; Stolzenburg et al. 2018). 


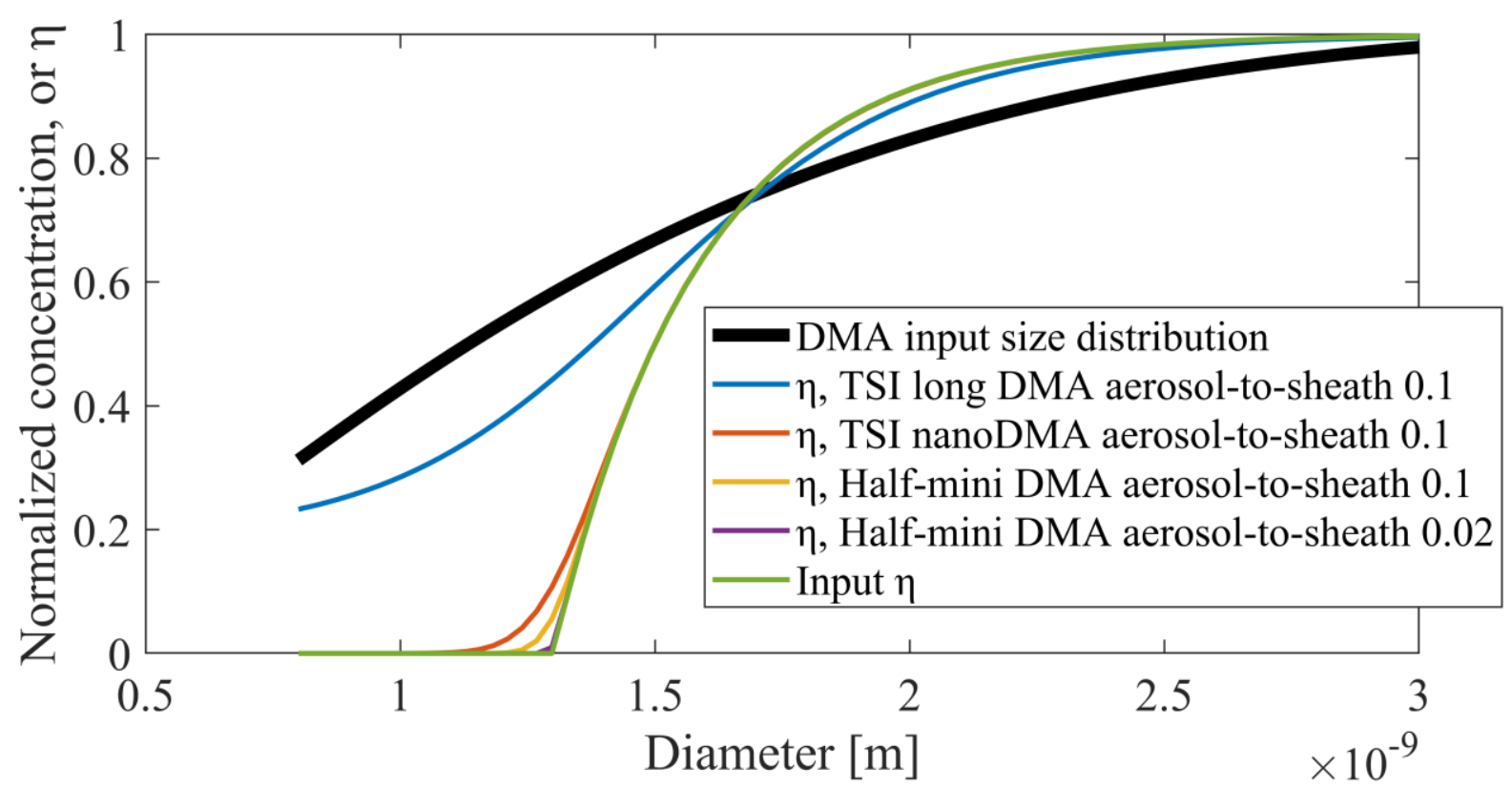

Figure 12. Simulated CPC calibration using various DMA resolution.

Sample flow pressure

Reports on the performance of ultrafine CPCs at low pressures are quite limited. Four publications were found, in which the sample flow pressure was reduced by using a valve or orifice to restrict the sample flow between the DMA and the CPC and AEM. The first one is by Saros et al. (1996) whose focus was the performance of the PHA under low pressure. They found changes in the absolute pulse heights, while the relative differences in the peak pulse height MCA channels stayed quite constant throughout the studied pressure range. 20 years later, Takegawa et al. (2017) published experiments on verification of the aerosol flow rate of the TSI 3776 for low pressure conditions by measuring the mass flow rate at the inlet, sheath channel and optics to correct the pressure dependent flow rate changes. Their results show quite small differences in the cut-off of the 3776 with varying pressure, confirming its use in airborne measurements with proper capillary flow calibration.

The first report of low pressure experiments for a mixing type CPC is by Kim et al. (2002), studying the operation of their PSM down to around $10 \mathrm{kPa}$. They conclude that the optimal operation conditions for a mixing CPC are similar in low and ambient pressure conditions, and that at decreasing pressure the decrease in the detection efficiency is due to decreased particle growth time in the condenser. Even at pressure of $15 \mathrm{kPa}$ their PSM detected $40 \%$ of $3 \mathrm{~nm}$ particles compared to $85 \%$ at atmospheric pressure. For the Airmodus A11, Kangasluoma et al. (2016b) report its operation characterization down to $50 \mathrm{kPa}$, which corresponds to a typical pressure at the maximum altitude that their group has performed flights with a Cessna aircraft. They show that the largest changes in the instrument operation are in the A20 CPC detection efficiency, which decreases at pressures below 60 $\mathrm{kPa}$ rapidly. The A11 cut-off was shown to be constant in the pressure range of 60-100 kPa within the experimental uncertainties.

Response time

For the CPC response time calibration, we mainly summarize the findings of Enroth et al. (2018), who investigated the methods and their flaws to determine the CPC response time. The suggested definition for the response time is $3 \tau$, where $\tau$ is the time constant in the exponential decay curve when the sampled concentration is rapidly brought from constant value to 0 . Thus, $3 \tau$ represents the time that 
is required for the concentration to decay from the initial value to $5 \%$ of the initial value. They also list challenges related to each of the experimental methods concerning the response time determination. Erroneous response times are potentially obtained with the spark method if the used concentration is too high to saturate the optics, the particle pulse is too transient for a CPC to follow its increase or decrease, or the particles are too small or about the size of the CPC cut-off. Using a fast valve is a simple method to obtain sharp change in the particle concentration, while it creates discontinuity in pressure that can affect e.g. some sheathed instruments. Further, in the experimental setup all flows has to be turbulent to avoid flow smearing, particle concentrations low enough for not causing coincidence in the optics and test particles above the CPC cut-off to avoid biases due to flow and supersaturation profiles inside the CPC.

The suggested method for inducing the rapid concentration change is a fast valve with switching time of $2 \mathrm{~ms}$ (or less). The sub-3 nm CPCs can be grouped to three based on their measured response times. The two-stage CPCs, the TSI 3777 and Airmodus A11, are the slowest sub-3 nm CPCs, the response times being around 1.5-2 s. The second group are the boosted non-sheathed laminar CPCs of response times around 0.5-1 s. These include boosted laminar CPCs with increased flow rates, such as the ADI $1 \mathrm{~nm}$ CPC or the B3010. The fastest CPCs are the sheathed laminar CPCs reaching response times even down to 100 ms or below, such as the TSI 3776 and 3788, and the Kanomax Fast CPC with response times of around 100, 120, and $60 \mathrm{~ms}$, respectively.

The response time is determined by the travel time difference of the fastest and slowest particles, and in the sheathed instruments, the travel time profile is very uniform due to absence of slow particles close to the walls. The drawback of the sheathed instruments is the low counting statistics due to low aerosol flow rate. Thus, careful consideration is suggested when optimizing the selection of instrument between the response time and counting statistics.

Table 1. CPC response times [s] as measured by Enroth et al. (2018).

\begin{tabular}{|c|c|c|c|c|c|}
\hline CPC & $\begin{array}{l}\text { Working } \\
\text { fluid }\end{array}$ & Instrument type & $\begin{array}{l}\text { Spark, } \\
\text { decay }\end{array}$ & $\begin{array}{l}\text { Valve, } \\
\text { increase }\end{array}$ & $\begin{array}{l}\text { Valve, } \\
\text { decay }\end{array}$ \\
\hline ADI wVCPC & Water & Laminar, sheathed & 0.68 & - & - \\
\hline Airmodus A11 & DEG & Mixing, two stage & - & $1.62-1.74$ & $1.48-1.72$ \\
\hline Airmodus A20 & Butanol & $\begin{array}{l}\text { Laminar, } \\
\text { unsheathed } \\
\text { Laminar, }\end{array}$ & 1.15 & 1.13 & 1.08 \\
\hline B3010 & Butanol & $\begin{array}{l}\text { unsheathed } \\
\text { Laminar, }\end{array}$ & 2.32 & - & - \\
\hline B3010 (1.6 lpm) & Butanol & $\begin{array}{l}\text { unsheathed } \\
\text { Laminar, }\end{array}$ & 0.91 & - & - \\
\hline TSI 3010 & Butanol & $\begin{array}{l}\text { unsheathed } \\
\text { Laminar, }\end{array}$ & 1.37 & 2.07 & 2.26 \\
\hline TSI 3772 & Butanol & unsheathed & 0.89 & 1.32 & 1.3 \\
\hline TSI 3776 & Butanol & $\begin{array}{l}\text { Laminar, sheathed } \\
\text { Laminar, two }\end{array}$ & 0.09 & 0.09 & 0.1 \\
\hline TSI 3777 & DEG & stage & 1.94 & - & - \\
\hline TSI 3788 & Water & Laminar, sheathed & - & 0.12 & 0.12 \\
\hline UHEL FCPC & Butanol & Mixing & 0.35 & - & - \\
\hline
\end{tabular}

Cut-off

The principle of defining the cut-off for a sub-3 nm CPC is based on similar calibration setup as reported by Liu and Pui (1974): concentration measured by the test CPC is compared against a reference aerosol 
electrometer for size selected charged particles. As suggested above, the DMA size resolution is beneficiary to be above 10 to avoid sizing artifacts. Besides the DMA resolution, as shown by many separate reports, in sub-3 nm size range the chemical composition of the test particles is at least as important as the particle mobility diameter in determining the detection efficiency. Thus, our discussion is mostly focused on the fluid-particle pairs, and briefly their practical implications.

Ion induced nucleation

Already a century ago, (Wilson 1897; 1899) reported that more fog is formed in an expansion chamber when negative ions are present compared to the presence of positive ions, and also more fog formation in the presence of bipolar ions compared to no ions at all. From the mechanistic point of view, this process is the same as is the CPC cut-off calibration: condensation of vapor onto charged or neutral seeds, with exception that the seeds used by Wilson were not size nor chemically classified. A few similar reports after Wilson have been published in which ion-induced nucleation has been studied by creating the ions inside the chamber (e.g. Adachi et al. 1992; Kane et al. 1995; Rabeony and Mirabel 1987), while such chamber studies cannot resolve completely the ion induced nucleation problem due to lack of ion classification. Stolzenburg and McMurry (1991) are possibly the first to report observation of higher detection efficiency (ion induced nucleation probability) for size selected negatively charged particles than positively charged particles, while they conclude that this observation may well be an experimental artifact. Based on the following discussion, retrospectively, their observation may have been correct. Bartz et al. (1985) also studied electrically neutral size classified particles, but reported no difference in the detection efficiency as compared to charged particles due to lack of sufficient instrumental accuracy.

Seto et al. (1997) are the first one to report ion induced nucleation experiments for strictly monomobile ions of around $1 \mathrm{~nm}$ in size, made possible by the combination of electrosprayed ions, high resolution DMA and their PSM, as discussed previously. They found that singly positively charged alkylhalide, ionic liquid and some other type of salts can be detected via condensation methods at the onset of homogeneous nucleation of DPB, while negatively charged ions were not detected at all. As other groups obtained the high resolution DMAs, which were used to calibrate sub-3 nm CPCs, more reports were published on similar ion induced nucleation sign preferences (Hering et al. 2017; Iida et al. 2009; Kangasluoma et al. 2013; Kangasluoma et al. 2014; Kuang et al. 2012b; Sipilä et al. 2009; Winkler et al. 2008a). Few of these studies report similar finding as Stolzenburg and McMurry two decades earlier that the detection efficiency is higher for negative than positive particles for butanol at around 3 $\mathrm{nm}$ size. Of these publications, Winkler et al. (2008a) studied also particles that were neutralized from the size selected charged particles, and observed that the charged particles (with negative sign preference) were activated at lower supersaturation than the neutral ones. By examining the size selected neutralized particles using three different particle and condensing fluid compositions, Kangasluoma et al. (2016c) showed that the particle and condensing vapor chemistry related factors are governing heterogeneous nucleation over particle charging state or possibly even mobility equivalent size. Tauber et al. (2018) reports the most recent CPC related ion induced nucleation experiment, in which they nucleated butanol onto singly charged atoms at saturation ratios below what is required for homogenous nucleation. Their results agree well with the Kelvin-Thomson theory.

Working fluids

Butanol is traditionally the most used working fluid, and the detection efficiencies are the least dependent on the particle composition (Kangasluoma et al. 2014; Kangasluoma et al. 2016c; Kulmala et al. 2007; Kupc et al. 2013a), mostly because of the ability to activate some hydrocarbon species that DEG and water cannot activate that well. This may be due to that butanol is not polar like water, but more nonpolar similar to the test hydrocarbon ions such as THABr. On the other hand, high 
detection efficiencies without significant homogeneous nucleation have not been reported at $1 \mathrm{~nm}$ for butanol, except very recently by Barmpounis et al. (2018), who lowered the condenser temperature of their CPC down to $2{ }^{\circ} \mathrm{C}$. This observation is supported by Tauber et al. (2018) who report detection of monoatomic ions at butanol saturation ratio of around 4.6, which is below the homogeneous nucleation saturation ratio of 5-6 (Viisanen and Strey 1994). DEG and water exhibit similar responses to particle composition: very efficient activation of salts while poor activation of hydrocarbons (Jiang et al. 2011b; Kangasluoma et al. 2017; Kangasluoma et al. 2014; Kuang et al. 2012b). The main difference to butanol is that the cut-off for certain types of hydrocarbon particles is considerably larger than for example for $\mathrm{NaCl}$. This observation can be partly biased due to lack of well characterized sources sub-3 nm of hydrocarbon test particles. Thus, the selection between butanol and water/DEG as the working fluid can be roughly simplified as follows: butanol yields more stable response to particle chemical composition, while increasing the detection efficiency at $1 \mathrm{~nm}$ is challenging due to homogeneous nucleation. On the other hand, water and DEG can activate particles close to $1 \mathrm{~nm}$ depending on the particle chemical composition without significant amount of homogeneous nucleation, but the cut-off is highly dependent on the chemical composition.

The work with the water CPCs (at the latest) showed that the CPC response is sensitive to the composition of the sampled aerosol particles. Similarly, O'Dowd et al. (2004) notes that the chemical composition of the test aerosol will affect the pulse height distributions of the droplets grown by butanol. Therefore, it is evident that the composition of the test particles will have a significant effect on the CPC cut-off diameter. Indeed, the composition-dependent cut-off has been utilized in CPCb type instruments aiming to infer information about the chemical composition of atmospheric aerosol (Kangasluoma et al. 2014; Kulmala et al. 2007; Riipinen et al. 2009). The operation principle is that two CPCs with two different working fluids can be tuned for identical performance in activating insoluble aerosol particles (often Ag in laboratory characterizations), while solubility effects lower the cut-off of the other CPC for specific particles. Practically, for example, when a butanol and a water based CPC are tuned to exhibit a similar cut-off curve for insoluble Ag particles, the water based CPC can detect smaller particles of $\mathrm{NaCl}$ than the butanol $\mathrm{CPC}$ due to $\mathrm{NaCl}$ solubility in water.

Relative humidity

Of the three most commonly used CPC working fluids, the detection efficiency given by butanol and DEG are affected by the sample flow water concentration, while water based CPCs are not. Iida et al. (2009) noted that the sample flow relative humidity affects the detection efficiency of $2.3 \mathrm{~nm}$ $\mathrm{Ag}$ particles, interestingly so that increasing humidity increased detection efficiency when using propylene glycol, while detection efficiency decreased when the working fluid was ethylene glycol. Both in the first DEG SMPS (Jiang et al. 2011b) and in the improved DEG SMPS (Cai et al. 2019; Cai et al. 2017b), a Nafion semi-permeable membrane (PERMA PURE LLC) was installed in the DEG CPC saturator flow (before the saturator) to prevent the influence of the sample flow relative humidity. Kangasluoma et al. (2013) performed similar experiments for DEG, finding positive correlation between the sample flow relative humidity and detection efficiency when conducting the experiments using the Airmodus A11. These effects in the A11 have been studied more in detail by Ahonen et al. (2019), who modeled the effect of water vapor on the detection efficiency using computation fluid dynamics and classical nucleation theory. With the TSI 3777, however, the relative humidity does not affect the cutoff, most probably because the sheath flow is dried and the fraction of humid flow entering the condenser is relatively smaller than in the A11 (Kangasluoma et al. 2017). Tauber et al. (2019a) characterized the sample flow humidity effects to the TSI 3776, finding that increase in humidity increased the detection efficiency for $\mathrm{NaCl}$ particles, but did not affect, or at most increased substantially less the detection of Ag particles.

Cut-off vs. detected particle concentration 
Kangasluoma and Kontkanen (2017) carried out numerical simulations on the effect of uncertain cut-off on the detected particle number concentration. Because of the highly varying particle number concentration as a function of size in the sub- $3 \mathrm{~nm}$ size range in systems producing new particles, fractions of nanometers error in the cut-off can cause significant error in the detected concentration. All other things being equal, in humid environments the number of detected particles will be higher because the cut-off is decreased by the higher humidity. When combining the effects caused by the effect of particle composition and relative humidity on the cut-off and subsequently to the detected concentration, the comparability of long-term measurements, as well as comparability of independent measurements at different sites and experiments poses one of the largest challenges for the sub- $3 \mathrm{~nm}$ measurement community.

Another aspect of this relation is that particle concentration can affect the cut-off of the CPC. Lewis and Hering (2013) studied in detail how cut-off of water based CPCs is affected by increasing particle concentration, showing clear increase in the cut-off mainly due to condensational heat release and less due to vapor depletion, leading to decreased supersaturation levels inside the growth tube. The increase in the CPC cut-off was shown to be up to around $5 \mathrm{~nm}$, depending on the CPC geometry, when the particle concentration increased from 0 to $200000 \mathrm{~cm}^{-3}$.

\section{Vapor adsorption}

Comprehensive efforts to tackle the composition dependency problem are lacking. Particle solubility and wettability to the condensing liquid possibly plays some role in determining the activation probability, as e.g. $\mathrm{NaCl}$ is well detected with water while nonpolar hydrocarbons not as well. On the other hand, Attoui (2018) showed experiments with three quite similar alkylhalides (Ude and Fernandez de la Mora 2005), of which detection efficiencies with butanol did not correlate with water solubility. Winkler et al. (2012) have reported that some butanol molecules adsorb onto the ion surface before nucleation. Oberreit et al. (2015) and Li and Hogan (2017) have studied the vapor uptake of selected nanoparticle-vapor systems, finding ion composition dependencies in the uptake. These observations have not yet been connected to heterogeneous nucleation studies.

\section{Cluster generation}

We discuss the cluster production methods in the scope of CPC calibrations, limiting the discussion to reports in which the cluster chemical composition has been directly measured or can be inferred from the mobility spectrum. This is because the cluster composition plays such a crucial role in determining the activation efficiency, and the particle composition is not necessarily exactly the same as of the starting material, can also vary with size or polarity, and is sensitive to impurities present in the system (Kangasluoma et al. 2013). Some cluster composition measurements exist from industrial or other sources but not applied to CPC calibrations (Fang et al. 2017; 2018; Wang et al. 2017b), while some sources have been shown to produce sub-3 nm particles but the cluster composition has not been verified with direct mass spectrometric measurement (Alanen et al. 2015; Carbone et al. 2016; Feng et al. 2016; Maisser et al. 2015a). Such efforts or sources are not included in this discussion. Use of charger ions as test ions are also omitted because of their chemical variability with the trace gases (Maisser et al. 2015b; Steiner et al. 2014; Steiner and Reischl 2012). In addition, some chamber experiments may be considered as well characterized cluster sources, such as the CLOUD chamber in CERN (Kirkby et al. 2011, and many subsequent publications), while generally the particle concentrations in the chambers are too low for CPC calibrations, which is why also no calibration experiments have been reported using chambers as particle source (except for Wimmer et al. 2015). As is obvious from the discussion below, not a large variety of well-characterized cluster sources are currently available for CPC calibrations. 
The electrospray (ES) method produces charged droplets by ripping liquid, which is at high potential, out of a thin capillary needle (Cloupeau and Prunet-Foch 1994). The electrically conductive liquid, to which the sample is dissolved, forms highly charged volatile droplets. Immediately after formation, the droplets begin to evaporate, increasing the charge-to-volume ratio until it reaches the Rayleigh limit and the droplet explodes because of Coulomb repulsion. Unipolar charged gas-phase molecules and clusters are formed as a result of ion evaporation from the droplet, or as charged residue after series of coulomb explosions and solvent evaporation (Kebarle and Verkerk 2009). The ES can be used to produce practically any liquid or solid samples that are soluble in some liquid.

The electrospray was the first source that has been applied in CPC experiments with known cluster composition (Seto et al. 1997). In the case of the electrospray, it is not always necessary to use mass spectrometric verification for the cluster composition, as the samples are often clean enough to generate distinct peaks in the mobility spectrum given by a high resolution DMA, which can be identified based on their electrical mobility. Such samples that have been, or could be used in CPC calibrations include for example tetra-alkyl ammonium salts (Ude and Fernandez de la Mora 2005), ionic liquids (Hogan and Fernandez de la Mora 2009) and proteins (Gamero-Castano and Fernandéz de la Mora 2002). The tetra-alkyl ammonium and ionic liquids form salts in the form of $\left(\mathrm{A}^{-} \mathrm{B}^{+}\right)_{n} \mathrm{~A}^{-}$and $\left(\mathrm{A}^{-} \mathrm{B}^{+}\right)_{n} \mathrm{~B}^{+}$, and are thus suitable for experiments in which it is necessary to know the exact chemical composition of the test aerosol (Figure 13). Large variety of salts with different combinations of A and B exist, making possible very detailed experiments on cluster-vapor interactions.

A standard electrospray cluster production suffers from the generation of highly charged droplets, of which electrical mobility diameter can be as low as $2 \mathrm{~nm}$, making the use of singly charged clusters around that mobility size impossible in CPC experiments. One of the most recent advances in electrospray cluster production is the bipolar electrospray source (Fernandez de la Mora and BarriosCollado 2017), in which one positive spray and negative spray are placed close to a grounded grid. Mixing of the two electrospray clouds produces bipolar cluster populations with minimal fraction of highly charged big droplets. The bipolar electrospray source gives access to clusters of both polarities with known composition. The neutralization efficiency of the bipolar electrospray, fraction of singly charged clusters, as well as its yield of neutral clusters is yet to be determined.

Steiner et al. (2017) used two electrosprays and high resolution DMAs to recombine two ions of opposite polarity, and studied the neutral recombination products. Such experimental scheme could be used in the future to study the neutral clusters of known composition, and their activation behavior in CPCs. 


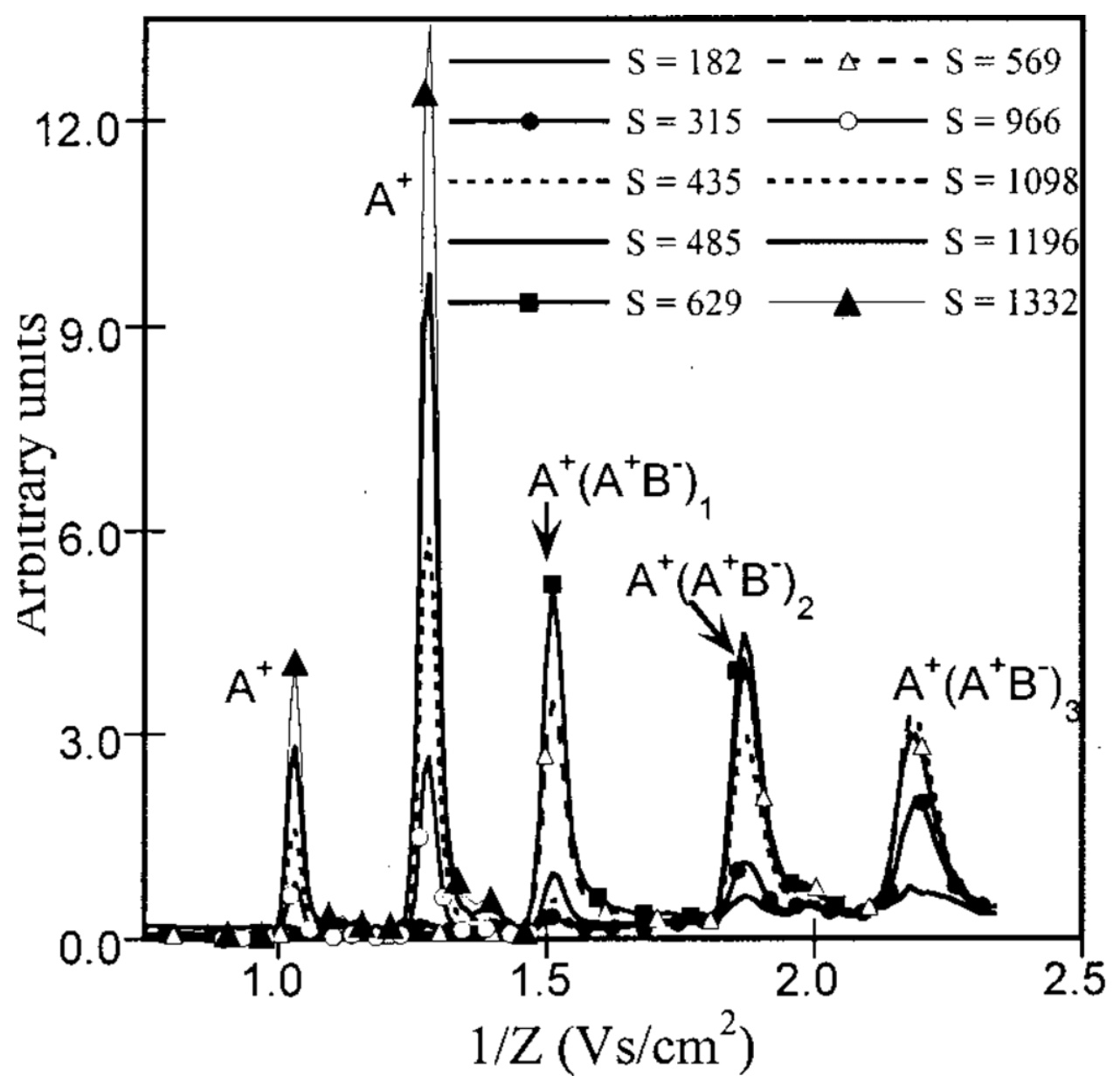

Figure 13. Electrosprayed tetraheptylammonium bromide clusters detected at various supersaturations (Gamero-Castano and Fernandéz de la Mora 2002) (Reproduced from Gamero-Castano, M. and Fernandéz de la Mora, J. (2002). Ion-induced nucleation: Measurement of the effect of embryo's size and charge state on the critical supersaturation. J Chem Phys 117:3345-3353 with the permission of AIP Publishing).

Tube furnace

The tube furnace as an aerosol source has been introduced by Scheibel and Porstendörfer (1983). Solid or liquid material is placed onto a ceramic boat inside a furnace, which is heated up. Material from the sample evaporates or sublimes to the gas stream, which is rapidly cooled down downstream of the furnace. The vapor becomes supersaturated and forms nanoparticles starting from the molecular clusters. The clusters and particles are charged usually with a radioactive source prior to size classification with a DMA.

Kangasluoma et al. (2013) has shown that by operating the furnace at relatively high flow rates (10-15 $\left.\mathrm{L} \mathrm{min}^{-1}\right)$, clusters down $1 \mathrm{~nm}$ are formed and reach the DMA at high enough concentrations to be used in CPC calibrations. With mass spectrometric analysis, they showed that in negative polarity heated ammonium sulfate produces mostly bisulfate clusters with a few ammonia molecules attached to them, sodium chloride produces $\mathrm{NaCl}$ clusters, while atomic silver clusters were contaminated by hydrocarbons. Some impurities, possibly hydrocarbon, were observed also in the bisulfate and $\mathrm{NaCl}$ clusters, which are easily introduced from either the carrier flow, the furnace tube surfaces or the sample itself. In the case of ammonium sulfate, clean production of the clusters results in distinct peaks also in the mobility spectrum, which are separated by one $\mathrm{HSO}_{4}$ molecule (Figure 14). Particle yield in those experiments was high enough to scavenge all ions generated by the charger, making it possible to use 
the clusters for CPC calibrations even at the charger ion mobility range. The furnace has been also shown to be suitable source for aerosolizing the alkylhalide salts often used in DMA calibrations, and is possibly suitable for producing many other desired samples (Kangasluoma et al. 2016c; Ude and Fernandez de la Mora 2005).

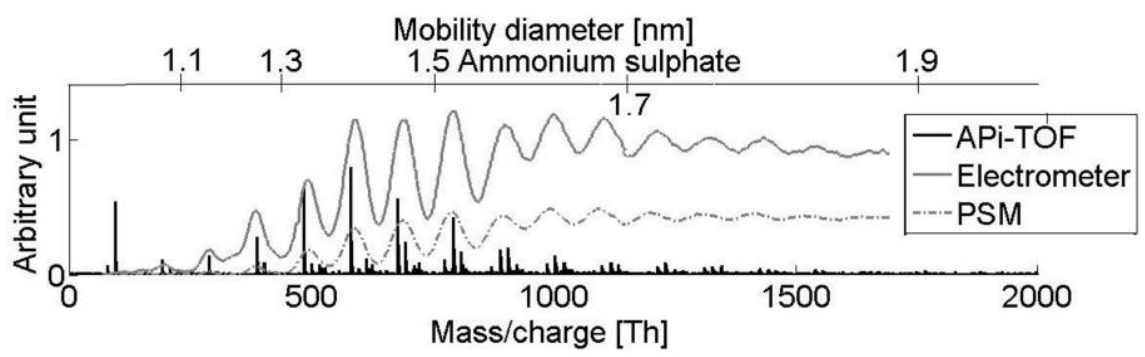

Figure 14. Mobility size scan overlaid with mass spectrometric measurement of negatively charged ammonium sulfate produced from with a tube furnace (modified from Kangasluoma et al. 2013) (Reproduced in modified form with permission of AAAR and AS\&T)

Glowing wire generator

Heating of metals has been known to produce aerosol particles for a long time (Nolan and Kennan 1949; Owen 1903). The glowing wire generator is often constructed so that a coil of a metal wire is placed inside a small chamber that is flushed with a carrier flow. High current is driven to the wire to resistively heat it. The metal reacts with oxygen in the carrier gas, forming metal oxides onto the metal surface. These metal oxides evaporate to the carrier flow, and form nanoparticles starting from the molecular clusters (Peineke et al. 2009). Some of the formed particles obtain charge during the formation process either from thermally emitted electrons (negative) or charged impurities that attach to the clusters, such as potassium (positive) (Peineke and Schmidt-Ott 2008). Thus, external charging of the nanoparticles is not always necessary when using this generator.

Kangasluoma et al. (2016c; 2015b) have reported that heating of a tungsten wire flushed with $\mathrm{N}_{2}$ produces negative $\left(\mathrm{WO}_{3}\right)_{\mathrm{x}} \mathrm{OH}^{-}$cluster series, and in positive similar tungsten trioxide clusters but which are clustered and charged with unidentified hydrocarbon contaminants. These clusters were formed without any external charging. Particle production from other wires has also been reported (Boies et al. 2011), but the cluster composition has not been verified by mass spectrometric measurements.

Flow tube

Even though only one report on cluster production experiment has been reported aiming for a CPC calibration (Kangasluoma et al. 2014), we discuss this cluster source due to its potential to probe more accurately the clusters produced by gas-phase chemical reactions, which possibly have the most relevance to atmospheric measurements. In the mentioned experiments, Kangasluoma and coworkers run ozonolysis of limonene in a medium sized flow tube, finding products consisting of approximately $10,20,30,40$ and so on carbon atoms, and various numbers of hydrogen and oxygen atoms. The importance of these experiments is that the observed cut-off for the CPCs was in the range of 2-3 nm, around 1-2 nm larger than for other calibration compounds used in the study. This significantly larger cut-off sets limitations for the use of CPCs in detecting such species down to $1 \mathrm{~nm}$, mainly that the supersaturation has to be possibly so high that significant amount of homogeneous nucleation takes place.

10 Workshops 
CPC workshop in Lund

Wiedensohler et al. (1994) report results from an ultrafine CPC workshop organized in Lund University in which four instruments aimed for sub-10 nm particle size distribution measurements were compared: The temperature scanning CPC of McDermott and a PHA CPC by Stolzenburg from University of Minnesota, ultrafine differential mobility particle sizer (DMPS) from University of Lund, and ultrafine diffusion battery from University of Washington. All four instruments utilized the TSI 3025A (or its prototype) as the detector. Not only was the goal of the workshop an instrumental comparison with four independent methods for sub-10 nm particle sizing, but to achieve an agreement in the measured size distributions in the artic on an icebreaker where particle concentrations are extremely low, which they did with remarkable success. Such efforts on instrumental comparisons for sub-10 nm particle size distributions are in high demand even today, as shown for example in the Figure 5 of Wiedensohler et al. (2012). They further discuss the statistical uncertainties of a DMPS system due to randomness in particle counting, which originates from the random distribution of particles in air. Very low particle charging efficiency for sub-10 nm particles in bipolar chargers and low particle penetration in the instrument were identified as the main causes for this challenge.

CPC workshop in Helsinki

A CPC workshop was organized in Helsinki in 2016, in which the TSI 3777, ADI vWCPC and prototype B3010 were characterized for their cut-off, and the response times of these and several other CPCs were determined (Enroth et al. 2018; Kangasluoma et al. 2017). The 3777 and vWCPC exhibited almost identical cut-off for all experiments conducted with tungsten oxide particles, ranging from 1.3 to $2.4 \mathrm{~nm}$ depending on the $\Delta \mathrm{T}$ settings and particle charging state, and from 2.5 to $3.3 \mathrm{~nm}$ for positively charged tetradodecylammonium ions. The cut-off for neutral particles was found 0.1-0.7 nm larger than for charged particles. The results of the CPC response time experiments are discussed more in detail in the calibration section.

\section{Summary tables}

Table 2. Summary of the laminar flow CPCs (reference with * notes the original instrument description)

\begin{tabular}{|c|c|c|c|c|c|c|}
\hline $\begin{array}{l}\text { Instruments } \\
\text { involved }\end{array}$ & $\begin{array}{l}\text { CPC } \\
\text { operation } \\
\text { principle }\end{array}$ & $\begin{array}{l}\text { Working } \\
\text { fluid(s) }\end{array}$ & $\begin{array}{l}\mathrm{d} 50 \\
{[\mathrm{~nm}]}\end{array}$ & $\begin{array}{l}\text { Calibration } \\
\text { compound(s) }\end{array}$ & Reference & Brief comment \\
\hline Proto & Laminar & Butanol & $\begin{array}{l}2.5- \\
3\end{array}$ & $\mathrm{NaCl}$ & $\begin{array}{l}\text { *Stolzenburg } \\
\text { \& McMurry } \\
1991\end{array}$ & First $3 \mathrm{~nm}$ CPC \\
\hline TSI 3025A & Laminar & Butanol & 3 & Silver, $\mathrm{NaCl}$ & $\begin{array}{l}\text { Kesten et al. } \\
1991\end{array}$ & $\begin{array}{l}\text { Calibration of } \\
\text { the commercial } \\
3025 \mathrm{~A}\end{array}$ \\
\hline Proto & Laminar & $\begin{array}{l}\text { Multifluor } \\
\text { APF }\end{array}$ & 3 & $\mathrm{NaCl}$ & $\begin{array}{l}\text { McDermott } \\
\text { et al. } 1991\end{array}$ & $\begin{array}{l}\text { Optimized } \\
\text { UFACNC with } \\
\text { fluorinated } \\
\text { compound. } \\
\text { Temperature } \\
\text { scan }\end{array}$ \\
\hline
\end{tabular}




\begin{tabular}{|c|c|c|c|c|c|c|}
\hline TSI 3010 & Laminar & Butanol & 5.7 & $\mathrm{Ag}$ & $\begin{array}{l}\text { Mertes et al. } \\
1995\end{array}$ & Tuning of $\Delta \mathrm{T}$ \\
\hline Proto & Laminar & Butanol & 3 & $\begin{array}{l}\text { Not } \\
\text { mentioned }\end{array}$ & $\begin{array}{l}\text { *Marti et al. } \\
1996\end{array}$ & First PHA CPC \\
\hline TSI 3020 & Laminar & Butanol & 3 & $\begin{array}{l}\mathrm{NaCl}, \mathrm{H} 2 \mathrm{SO} 4 \\
\text { WO3 }\end{array}$ & $\begin{array}{l}\text { Saros et al. } \\
1996\end{array}$ & $\begin{array}{l}\text { Characterization } \\
\text { of PHA CPC }\end{array}$ \\
\hline TSI 3785 & Laminar & Water & $4-30$ & $\begin{array}{l}\text { Oleic acid, } \\
\text { oxalic acid, } \\
\text { ammonium } \\
\text { sulfate, } \\
\text { laboratory } \\
\text { air }\end{array}$ & $\begin{array}{l}\text { *Hering et } \\
\text { al. } 2005\end{array}$ & $\begin{array}{l}\text { First water } \\
\text { based laminar } \\
\text { flow CPC }\end{array}$ \\
\hline $\begin{array}{l}\text { TSI 3785, } \\
3786,3782\end{array}$ & Laminar & Water & $\begin{array}{l}2.4- \\
30\end{array}$ & $\begin{array}{l}\text { Sucrose, } \\
\text { ambient } \\
\text { particles, Ag, } \\
\mathrm{NaCl}, \mathrm{DOS}, \\
\mathrm{DOP} \text {, emery } \\
\text { oil }\end{array}$ & $\begin{array}{l}\text { *Liu et al. } \\
2006\end{array}$ & $\begin{array}{l}\text { Sheathed } \\
\text { condenser } \\
\text { water based } \\
\text { laminar CPC }\end{array}$ \\
\hline TSI 3785 & Laminar & Water & $\begin{array}{l}3.5- \\
6\end{array}$ & $\begin{array}{l}\mathrm{Ag}, \\
(\mathrm{NH} 4) 2 \mathrm{SO} 4, \\
\mathrm{NaCl}\end{array}$ & $\begin{array}{l}\text { Petäjä et al. } \\
2006\end{array}$ & $\Delta \mathrm{T}$ tuning \\
\hline TSI 3786 & Laminar & Water & 3 & $\begin{array}{l}\text { Atmospheric } \\
\text { aerosol }\end{array}$ & $\begin{array}{l}\text { lida et al. } \\
2008\end{array}$ & $\begin{array}{l}\text { Comparison to } \\
3025 \text { with } \\
\text { atmospheric } \\
\text { aerosol }\end{array}$ \\
\hline $\begin{array}{l}\text { PHA 3025A, } \\
\text { proto }\end{array}$ & $\begin{array}{l}\text { Laminar, } \\
\text { expansion }\end{array}$ & $\begin{array}{l}\text { Butanol, } \\
\text { water }\end{array}$ & & $\begin{array}{l}\text { WO3, } \\
\text { atmospheric } \\
\text { aerosol }\end{array}$ & $\begin{array}{l}\text { Sipilä et al. } \\
2008\end{array}$ & $\begin{array}{l}\text { Applicability of } \\
\text { CPCs to detect } \\
\text { atmospheric } \\
\text { clusters }\end{array}$ \\
\hline PHA 3025A & Laminar & Butanol & $2-3$ & $\begin{array}{l}\text { WO3, } \\
\text { alkylhalides, } \\
\text { NiCr, charger } \\
\text { ions }\end{array}$ & $\begin{array}{l}\text { Sipilä et al. } \\
2009\end{array}$ & $\begin{array}{l}\text { Laboratory } \\
\text { verification of } \\
\text { the PHA CPC }\end{array}$ \\
\hline DEG 3025A & Laminar & $\begin{array}{l}\text { DEG, EG, } \\
\text { PEG, oleic } \\
\text { acid, DOS }\end{array}$ & $1-2$ & $\begin{array}{l}\mathrm{NaCl}, \\
(\mathrm{NH} 4) 2 \mathrm{SO} 4, \\
\mathrm{Ag}\end{array}$ & $\begin{array}{l}\text { *lida et al. } \\
2009\end{array}$ & $\begin{array}{l}\text { Theoretical and } \\
\text { experimental } \\
\text { analysis of } \\
\text { various working } \\
\text { fluids }\end{array}$ \\
\hline DEG 3776 & Laminar & DEG & $2-3$ & $\begin{array}{l}(\mathrm{NH} 4) 2 \mathrm{SO} 4, \\
\mathrm{H} 2 \mathrm{SO} 4\end{array}$ & $\begin{array}{l}\text { Wimmer et } \\
\text { al. } 2015\end{array}$ & $\begin{array}{l}\text { Low } \\
\text { temperature } \\
\text { CPC calibration }\end{array}$ \\
\hline Proto & Laminar & Water & 3 & $\mathrm{Zn}$ & $\begin{array}{l}\text { *Hwang and } \\
\text { Ahn } 2017\end{array}$ & $\begin{array}{l}\text { "Wrong" dT } \\
\text { setting, } \\
\text { miniaturized }\end{array}$ \\
\hline PUFP & Laminar & Water & ? & - & $\begin{array}{l}{ }^{*} \text { Asbach et } \\
\text { al. } 2017\end{array}$ & Miniaturized \\
\hline
\end{tabular}




\begin{tabular}{|c|c|c|c|c|c|c|}
\hline TSI 3776 & Laminar & Butanol & 3 & Sucrose & $\begin{array}{l}\text { Takegawa et } \\
\text { al. } 2017\end{array}$ & $\begin{array}{l}3776 \text { pressure } \\
\text { calibration }\end{array}$ \\
\hline ADI vWCPC & Laminar & Water & $1-2$ & $\begin{array}{l}\mathrm{NiCr}, \mathrm{NaCl}, \\
\text { (NH4)2SO4, } \\
\text { sucrose }\end{array}$ & $\begin{array}{l}\text { *Hering et } \\
\text { al. } 2017\end{array}$ & $\begin{array}{l}\text { Three stage } \\
\text { water CPC }\end{array}$ \\
\hline Palas CPC & Laminar & DEG & 1.6 & $\begin{array}{l}(\mathrm{NH} 4) 2 \mathrm{SO} 4, \\
\text { charger ions }\end{array}$ & *Kuang 2018 & $\begin{array}{l}\text { First DEG PHA } \\
\text { CPC }\end{array}$ \\
\hline $\begin{array}{l}\text { ADI Magic } \\
\text { CPC }\end{array}$ & Laminar & Water & 5 & $(\mathrm{NH} 4) 2 \mathrm{SO} 4$ & $\begin{array}{l}\text { *Hering et } \\
\text { al. } 2018\end{array}$ & $\begin{array}{l}\text { Self-sustained } \\
\text { water CPC }\end{array}$ \\
\hline TSI 3776 & Laminar & Butanol & $\begin{array}{l}1.5- \\
2 \\
\end{array}$ & $\mathrm{NiCr}$ & Attoui 2018 & $\begin{array}{l}\Delta \mathrm{T} \text { and flow } \\
\text { rate tuning. }\end{array}$ \\
\hline TSI 3776 & Laminar & Butanol & 2 & alkylhalides & $\begin{array}{l}\text { Barmbounis } \\
\text { et al. } 2018\end{array}$ & $\Delta \mathrm{T}$ tuning. \\
\hline TSI 3010 & Laminar & Butanol & 3 & $\begin{array}{l}\text { WO3, } \\
\text { alkylhalides }\end{array}$ & $\begin{array}{l}\text { Picard et al. } \\
2018\end{array}$ & Tuned 3010 \\
\hline $\begin{array}{l}\text { Kanomax } \\
3650\end{array}$ & Laminar & Butanol & 2 & $?$ & & $\begin{array}{l}\text { Fast response } \\
\text { time }\end{array}$ \\
\hline
\end{tabular}

Table 3. Summary of the mixing type CPCs (reference with * notes the original instrument description)

\begin{tabular}{|c|c|c|c|c|c|c|}
\hline $\begin{array}{l}\text { Instruments } \\
\text { involved }\end{array}$ & $\begin{array}{l}\text { CPC } \\
\text { operation } \\
\text { principle }\end{array}$ & $\begin{array}{l}\text { Working } \\
\text { fluid(s) }\end{array}$ & $\begin{array}{l}\mathrm{d} 50 \\
{[\mathrm{~nm}]}\end{array}$ & $\begin{array}{l}\text { Calibration } \\
\text { compound(s) }\end{array}$ & Reference & Brief comment \\
\hline Proto & Mixing & DBP & 1 & alkylhalides & $\begin{array}{l}\text { *Seto et al. } \\
1997\end{array}$ & $\begin{array}{l}\text { First CPC experiment } \\
\text { with monomobile } \\
\text { ions }\end{array}$ \\
\hline Proto & Mixing & DBP & 3 & $\mathrm{NaCl}$ & $\begin{array}{l}\text { *Mavliev } \\
\text { and Wang } \\
2000\end{array}$ & $\begin{array}{l}\text { Grown droplet } \\
\text { measurements }\end{array}$ \\
\hline Proto & Mixing & DBP & 1 & $\begin{array}{l}\text { Alkylhalides, } \\
\text { proteins }\end{array}$ & $\begin{array}{l}\text { *Gamero } \\
\text { and } \\
\text { Fernandez } \\
\text { de la Mora } \\
2000\end{array}$ & $\begin{array}{l}\text { lon sizing using the } \\
\text { PSM }\end{array}$ \\
\hline $\begin{array}{l}\text { Kanomax } \\
\text { MTCPC }\end{array}$ & Mixing & EG & 3 & $\mathrm{NaCl}$ & $\begin{array}{l}\text { *Kim et al. } \\
2002\end{array}$ & $\begin{array}{l}\Delta \mathrm{T} \text { and flow rate } \\
\text { tuning. Experiments } \\
\text { at low pressure }\end{array}$ \\
\hline Proto & Mixing & DBP & 1 & $\begin{array}{l}\text { Alkylhalides, } \\
\text { proteins }\end{array}$ & $\begin{array}{l}\text { *Gamero } \\
\text { and } \\
\text { Fernandez } \\
\text { de la Mora } \\
2002\end{array}$ & $\begin{array}{l}\text { Ion induced } \\
\text { nucleation studies }\end{array}$ \\
\hline Proto & Mixing & DBP & $2-3$ & $\mathrm{NaCl}, \mathrm{Ag}$ & $\begin{array}{l}\text { *Mavliev } \\
2002\end{array}$ & Mixing CPC \\
\hline
\end{tabular}




\begin{tabular}{|c|c|c|c|c|c|c|}
\hline Proto & Mixing & EG & 1.6 & $\mathrm{Au}$ & $\begin{array}{l}\text { *Kim et al. } \\
2003\end{array}$ & $\begin{array}{l}\Delta T \text { and flow rate } \\
\text { tuning. }\end{array}$ \\
\hline Proto & Mixing & DBP & 1 & Alkylhalides & $\begin{array}{l}\text { *Sgro and } \\
\text { Fernandez } \\
\text { de la Mora } \\
2004\end{array}$ & T-shaped mixing \\
\hline Proto & Mixing & Butanol & 4 & $\mathrm{Ag}$ & $\begin{array}{l}\text { *Mordas et } \\
\text { al. } 2005\end{array}$ & $\begin{array}{l}\text { Swirling flow UF02 } \\
\text { proto }\end{array}$ \\
\hline Proto & Mixing & Butanol & 2 & $\mathrm{Ag}$ & $\begin{array}{l}\text { *Mordas et } \\
\text { al. } 2008 \mathrm{~b}\end{array}$ & $\begin{array}{l}\text { Swirling flow UF02 } \\
\text { proto, } \Delta T \text { tuning }\end{array}$ \\
\hline Proto & Mixing & EG & $4-5$ & $\mathrm{NaCl}$ & $\begin{array}{l}\text { *Ito et al. } \\
2011\end{array}$ & $\begin{array}{l}\text { Experiments vs. } \\
\text { model for a mixing } \\
\text { CPC }\end{array}$ \\
\hline $\begin{array}{l}\text { Airmodus } \\
\text { A10 }\end{array}$ & Mixing & DEG & $1-2$ & $\begin{array}{l}\text { Alkylhalides, } \\
\text { Ag, charger } \\
\text { ions, WO3 }\end{array}$ & $\begin{array}{l}\text { *Vanhanen } \\
\text { et al. } 2011\end{array}$ & $\begin{array}{l}\text { Field deployable and } \\
\text { commercial mixing } \\
\text { type CPC }\end{array}$ \\
\hline $\begin{array}{l}\text { Airmodus } \\
\text { A11 }\end{array}$ & Mixing & DEG & $\begin{array}{l}1.3- \\
1.7\end{array}$ & $\begin{array}{l}\text { (NH4)2SO4, } \\
\mathrm{NaCl}, \mathrm{Ag}, \\
\text { WO3 }\end{array}$ & $\begin{array}{l}\text { Kangasluoma } \\
\text { et al. } 2013\end{array}$ & $\begin{array}{l}\text { Effect of particle } \\
\text { composition and } \\
\text { sample flow RH on } \\
\text { cutoff }\end{array}$ \\
\hline Proto & Mixing & DEG & $2-3$ & $\begin{array}{l}\text { Alkylhalides, } \\
\text { ag }\end{array}$ & $\begin{array}{l}\text { *Kim et al. } \\
2015\end{array}$ & $\begin{array}{l}\text { Effect of nucleation } \\
\text { temperature to } \\
\text { cutoff }\end{array}$ \\
\hline $\begin{array}{l}\text { Airmodus } \\
\text { A11 }\end{array}$ & Mixing & DEG & $1-3$ & WO3 & $\begin{array}{l}\text { Kangasluoma } \\
\text { et al. } 2015\end{array}$ & $\begin{array}{l}\text { A11 inversion } \\
\text { verification and WO3 } \\
\text { source } \\
\text { characterization }\end{array}$ \\
\hline $\begin{array}{l}\text { Airmodus } \\
\text { A11 }\end{array}$ & Mixing & DEG & 1.6 & WO3 & $\begin{array}{l}\text { Kangasluoma } \\
\text { et al. } 2016\end{array}$ & $\begin{array}{l}\text { A11 pressure } \\
\text { calibration, core } \\
\text { sampling inlet } \\
\text { characterization }\end{array}$ \\
\hline Proto & Mixing & Water & 3.9 & $\mathrm{NaCl}$ & $\begin{array}{l}\text { *Romay et } \\
\text { al. } 2016\end{array}$ & $\begin{array}{l}\text { Spinning flow in } \\
\text { condenser }\end{array}$ \\
\hline Proto & Mixing & Butanol & 13 & $\mathrm{Ag}, \mathrm{NaCl}$ & $\begin{array}{l}\text { *Kwon et al. } \\
2019\end{array}$ & $\begin{array}{l}\text { Microelectrochemical } \\
\text { chip for saturator } \\
\text { and condenser, } \\
\text { miniaturized CPC }\end{array}$ \\
\hline
\end{tabular}

Table 4. Summary of the expansion type CPCs (reference with * notes the original instrument description)

\begin{tabular}{llllll}
\hline & CPC & Working & $\mathrm{d} 50$ & Calibration \\
$\begin{array}{l}\text { Instruments } \\
\text { involved }\end{array}$ & $\begin{array}{l}\text { operation } \\
\text { principle }\end{array}$ & $\begin{array}{l}\text { fluid(s) } \\
{[\mathrm{nm}]}\end{array}$ & $\begin{array}{l}\text { compound(s) } \\
\text { feference }\end{array}$ & $\begin{array}{l}\text { Brief } \\
\text { comment }\end{array}$ \\
\hline
\end{tabular}




\begin{tabular}{|c|c|c|c|c|c|c|}
\hline Proto & Expansion & Water & 3 & $\mathrm{H} 2 \mathrm{SO} 4, \mathrm{NaCl}$ & $\begin{array}{l}\text { *Kurten } \\
\text { et al. } \\
2005\end{array}$ & $\begin{array}{l}\text { Portable } \\
\text { expansion } \\
\text { CPC }\end{array}$ \\
\hline SANC & Expansion & Propanol & 1 & $\begin{array}{l}\text { WO3, } \\
\text { charger ions }\end{array}$ & $\begin{array}{l}\text { Winkler } \\
\text { et al. } \\
2008\end{array}$ & $\begin{array}{l}\text { Experiments } \\
\text { with neutral } \\
\text { particles }\end{array}$ \\
\hline VSANC & Expansion & $\begin{array}{l}\text { Propanol, } \\
\text { water }\end{array}$ & 4 & $\begin{array}{l}\text { WO3, } \\
\text { (NH4)2SO4 }\end{array}$ & $\begin{array}{l}\text { *Pinterich } \\
\text { et al. } \\
2016\end{array}$ & $\begin{array}{l}\text { Field } \\
\text { deployable } \\
\text { mixing type } \\
\text { CPC }\end{array}$ \\
\hline
\end{tabular}

Table 5. Summary of instrument calibrations including multiple instrument models (reference with * notes the original instrument description).

\begin{tabular}{lllllll}
$\begin{array}{l}\text { Instruments } \\
\text { involved }\end{array}$ & $\begin{array}{l}\text { CPC } \\
\text { operation } \\
\text { principle }\end{array}$ & $\begin{array}{l}\text { Working } \\
\text { fluid(s) }\end{array}$ & $\begin{array}{l}\mathrm{d} 50 \\
{[\mathrm{~nm}]}\end{array}$ & $\begin{array}{l}\text { Calibration } \\
\text { compound(s) }\end{array}$ & Reference & Brief comment \\
\hline Proto types & Laminar & Butanol & & $\begin{array}{l}\text { Atmospheric } \\
\text { aerosol }\end{array}$ & $\begin{array}{l}\text { Wiedensohler } \\
\text { et al. 1994 }\end{array}$ & CPC workshop \\
\hline TSI 3010 & Laminar & Butanol & 3.75 & $\mathrm{Ag}$ & $\begin{array}{l}\text { Wiedensohler } \\
\text { et al. 1997 }\end{array}$ & $\begin{array}{l}\text { CPC workshop. } \\
\text { Tuned 3010 }\end{array}$ \\
\hline $\begin{array}{l}\text { TSI 3786, } \\
3025\end{array}$ & Laminar & $\begin{array}{l}\text { Butanol, } \\
\text { Water }\end{array}$ & $\begin{array}{l}1.5- \\
3\end{array}$ & $\begin{array}{l}\mathrm{NaCl}, \\
(\mathrm{NH} 4) 2 \mathrm{SO} 4,\end{array}$ & $\begin{array}{l}\text { Kulmala et al } \\
\mathrm{Ag}\end{array}$ & $\begin{array}{l}\text { CPCb based on } \\
\text { water solubility } \\
\text { effects of cutoff }\end{array}$ \\
\hline
\end{tabular}

TSI 3786,

\begin{tabular}{|c|c|c|c|c|c|}
\hline $\begin{array}{l}3776,3772 \text {, } \\
3025,3010 \text {, }\end{array}$ & Laminar & Water & $2-4$ & $\begin{array}{l}\mathrm{Ag}, \\
(\mathrm{NH} 4) 2 \mathrm{SO} 4, \\
\mathrm{NaCl}\end{array}$ & $\begin{array}{l}\text { Mordas et al. } \\
2008 a\end{array}$ \\
\hline
\end{tabular}

\begin{tabular}{|c|c|c|c|c|c|c|}
\hline DEG 3025A & Laminar & DEG & $1-2$ & $\begin{array}{l}\mathrm{NaCl}, \mathrm{Ag}, \\
\text { alkylhalides }\end{array}$ & $\begin{array}{l}\text { *Jiang et al. } \\
2011\end{array}$ & $\begin{array}{l}\text { First DEG CPC } \\
\text { based SMPS }\end{array}$ \\
\hline $\begin{array}{l}\text { DEG 3025A, } \\
3025 \mathrm{~A}\end{array}$ & Laminar & $\begin{array}{l}\text { DEG, } \\
\text { butanol }\end{array}$ & $\begin{array}{l}1.5- \\
2.5\end{array}$ & $\begin{array}{l}\mathrm{NaCl}, \\
\text { alkylhalides, } \\
\text { WO3 }\end{array}$ & $\begin{array}{l}\text { Kuang et al. } \\
2012\end{array}$ & $\begin{array}{l}\Delta \mathrm{T} \text { and flow } \\
\text { rate tuning. }\end{array}$ \\
\hline $\begin{array}{l}\text { DEG 3776, } \\
\text { Airmodus } \\
\text { A11 }\end{array}$ & $\begin{array}{l}\text { Laminar, } \\
\text { mixing }\end{array}$ & DEG & $1-3$ & $\begin{array}{l}\mathrm{NaCl}, \mathrm{WO} 3, \\
\mathrm{H} 2 \mathrm{SO} 4, \\
\text { alkylhalides, } \\
\text { (NH4)2SO4 }\end{array}$ & $\begin{array}{l}\text { Wimmer et al. } \\
2013\end{array}$ & $\begin{array}{l}\Delta T \text { tuning, DEG } \\
\text { based } \\
\text { instrument } \\
\text { comparison }\end{array}$ \\
\hline $\begin{array}{l}\text { TSI } 3788, \\
3776\end{array}$ & Laminar & $\begin{array}{l}\text { Water, } \\
\text { butanol }\end{array}$ & $\begin{array}{l}2.2- \\
17.2\end{array}$ & $\begin{array}{l}\text { Sucrose, } \\
\mathrm{NaCl} \text {, candle, } \\
\text { emery oil, } \\
\text { proteins, } \mathrm{Ag}\end{array}$ & $\begin{array}{l}\text { Kupc et al. } \\
2013\end{array}$ & $\begin{array}{l}\text { Ultrafine CPC } \\
\text { characterization }\end{array}$ \\
\hline
\end{tabular}




\begin{tabular}{|c|c|c|c|c|c|c|}
\hline $\begin{array}{l}\text { TSI 3786, } \\
3776, \text { DEG } \\
\text { CPC, PSM }\end{array}$ & $\begin{array}{l}\text { Laminar, } \\
\text { mixing }\end{array}$ & $\begin{array}{l}\text { Butanol, } \\
\text { Water, } \\
\text { DEG }\end{array}$ & $1-3$ & $\begin{array}{l}\mathrm{NaCl}, \\
\text { (NH4)2SO4, } \\
\text { WO3, } \\
\text { sucrose, } \\
\text { candle, } \\
\text { limonene } \\
\text { ozonolysis }\end{array}$ & $\begin{array}{l}\text { Kangasluoma } \\
\text { et al. } 2014\end{array}$ & $\begin{array}{l}\text { CPC calibrations } \\
\text { with multiple } \\
\text { compounds }\end{array}$ \\
\hline $\begin{array}{l}\text { TSI } 3772 \\
\text { and } \\
\text { Airmodus } \\
\text { A20 }\end{array}$ & Laminar & Butanol & $3-4$ & WO3 & $\begin{array}{l}\text { Kangasluoma } \\
\text { et al. } 2015\end{array}$ & $\begin{array}{l}\Delta \mathrm{T} \text { tuning. Flow } \\
\text { rate tuning }\end{array}$ \\
\hline $\begin{array}{l}\text { Airmodus } \\
\text { A11, TSI } \\
3786,3776\end{array}$ & $\begin{array}{l}\text { Mixing, } \\
\text { laminar }\end{array}$ & $\begin{array}{l}\text { DEG, } \\
\text { butanol, } \\
\text { water }\end{array}$ & $\begin{array}{l}1- \\
2.5\end{array}$ & $\begin{array}{l}\text { (NH4)2SO4, } \\
\text { WO3, } \\
\text { alkylhalides }\end{array}$ & $\begin{array}{l}\text { Kangasluoma } \\
\text { et al. } 2016\end{array}$ & $\begin{array}{l}\text { Effect of charge } \\
\text { on cutoff }\end{array}$ \\
\hline $\begin{array}{l}\text { TSI 3777, } \\
\text { B3010, ADI } \\
\text { vWCPC }\end{array}$ & Laminar & $\begin{array}{l}\text { DEG, } \\
\text { water, } \\
\text { butanol }\end{array}$ & $1-3$ & $\begin{array}{l}\text { WO3, } \\
\text { alkylhalides }\end{array}$ & $\begin{array}{l}\text { Kangasluoma } \\
\text { et al. } 2017\end{array}$ & $\begin{array}{l}\text { CPC workshop, } \\
\text { calibration for } \\
\text { neutral cutoff }\end{array}$ \\
\hline $\begin{array}{l}\text { Airmodus } \\
\text { A11 }\end{array}$ & Mixing & DEG & $\begin{array}{l}1.4- \\
2\end{array}$ & $\begin{array}{l}\text { WO3, } \\
\text { alkylhalides }\end{array}$ & $\begin{array}{l}{ }^{*} \text { Kangasluoma } \\
\text { et al. } 2018\end{array}$ & $\begin{array}{l}\text { First Half-mini } \\
\text { and A11 based } \\
\text { DMPS }\end{array}$ \\
\hline
\end{tabular}

TSI 3776,

3777, 3010,

3772,

Airmodus

A20, ADI

$\begin{array}{ll}\text { Laminar, } & \text { DEG, } \\ \text { mixing } & \text { butanol, } \\ & \text { water }\end{array}$

$\mathrm{NaCl}$, metal

VWCPC,

oxides, Enroth et al.

CPC response

atmospheric 2018

time calibration

B3010

aerosol

\begin{tabular}{|c|c|c|c|c|c|c|}
\hline $\begin{array}{l}\text { SANC, TSI } \\
3776\end{array}$ & $\begin{array}{l}\text { Expansion, } \\
\text { laminar }\end{array}$ & Butanol & $2-3$ & $\mathrm{Ag}$ & $\begin{array}{l}\text { Tauber et al. } \\
2019\end{array}$ & $\begin{array}{l}3776 \\
\text { supersaturation } \\
\text { quantification } \\
\text { using the SANC }\end{array}$ \\
\hline $\begin{array}{l}\text { SANC, TSI } \\
3776\end{array}$ & $\begin{array}{l}\text { Expansion, } \\
\text { laminar }\end{array}$ & Butanol & $1-5$ & $\mathrm{Ag}, \mathrm{NaCl}$ & $\begin{array}{l}\text { Tauber et al. } \\
2019\end{array}$ & $\begin{array}{l}\text { Effect of } \\
\text { nucleation } \\
\text { temperature } \\
\text { and } \mathrm{RH} \text { on CPC } \\
\text { cut-off }\end{array}$ \\
\hline
\end{tabular}

\section{Future outlook}

Based on the review and discussions above, we have identified the following priorities for improving measurement accuracy and enabling new applications for CPCs:

1. CPC cut-off dependency on particle physical and chemical properties of the particle and condensing vapor. Uncertainties in the physical/chemical factors that determine size-dependent activation efficiencies are the greatest source of measurement uncertainty for sub-3 nm CPCs. Solutions to 
minimize the cut-off dependency on the particle composition would enhance the measurement accuracy significantly, especially in experiments in which the particle chemical composition is uncertain. Particle charging state also influences the cut-off, and there is a need to determine the smallest neutral particles or molecules that can be detected via heterogeneous nucleation for a specified condensing vapor. This limits understanding on the characterization of processes, such as combustion, in which the fraction of charged particles is high but unknown, because of the difficulties in interpreting and separating the signals from neutral and charged particles.

2. Cut-off dependency on sample air water concentration. Accuracy in long-term atmospheric monitoring experiments is affected by that the cut-off of butanol and DEG based CPCs is dependent on the sample air water concentration. Water concentration varies strongly with seasons and measurement locations, thus methods either adjusting the cut-off with varying water concentration or drying the sample air, as has been done for the DEG SMPSs (Cai et al. 2017b; Jiang et al. 2011b), would increase the stability of the cut-off.

3. Calibrations with atmospherically relevant test aerosols. Currently the two main challenges in this experiment are that the particle concentration in the atmosphere and the particle charging efficiencies below $3 \mathrm{~nm}$ are too low to obtain sufficient signal for a CPC calibration. Atmospherically relevant particle production methods, or charging methods with significantly higher charging efficiencies than the bipolar charge equilibrium, should be developed. These would significantly reduce the cut-off, and thus concentration related uncertainties in atmospheric measurements.

4. Easy to use and chemically reproducible cluster sources of singly charged particles for semicontinuous size distributions production in the size range of $1-5 \mathrm{~nm}$. The challenge with the electrospray is that it produces also highly charged droplets that overlap in mobility space with the test clusters. The bipolar electrospray source might resolve this, although this has not yet been demonstrated. For the spark generator, there are no published results on the cluster chemical composition. Furnace setups are very slow and sensitive to impurities in the system. The wire generator is the most robust generator to date, while its cluster yields have not been quantified and seem to vary from day to day, sometimes even down to levels of insufficient yield when producing tungsten oxides from residue oxygen in $\mathrm{N}_{2}$ gas (author's note).

5. High aerosol flow CPCs to increase DMPS statistics capable for sub-3 nm particle detection. As the current DMAs can accommodate high aerosol flow rates, correspondingly it will be useful in terms of the DMPS counting statistics and $\Pi$ parameter (Cai et al. 2019) to utilize CPCs with high aerosol flow rate to increase the number of counted particles via reduced losses and dilution.

6. One stage CPCs. Several reports show that $1 \mathrm{~nm} \mathrm{CPCs} \mathrm{do} \mathrm{not} \mathrm{necessarily} \mathrm{need} \mathrm{to} \mathrm{have} \mathrm{two} \mathrm{stages} \mathrm{to}$ grow the particles to optically detectable sizes (Barmpounis et al. 2018; Hering et al. 2017; Kim et al. 2003; Kuang 2018; Sgro and Fernandéz de la Mora 2004). For simplified operation and reduced price, one stage CPCs capable for $1 \mathrm{~nm}$ particle activation should be developed.

7. Supersaturation scan method for more extended size range. The current available methods for sizing based on the supersaturation scan method reach only up to $3 \mathrm{~nm}$ when the lowest cut-off is set to around $1 \mathrm{~nm}$. For obtaining overlap with instruments measuring size distributions above $3 \mathrm{~nm}$ that are more numerous, the upper cut-off of the supersaturation scan method based sizing should be extended above $3 \mathrm{~nm}$ while keeping the low cut-off at $1 \mathrm{~nm}$. Kangasluoma et al. (2016b) has demonstrated one solution for this by scanning the growth tube temperature of the Airmodus A10, reaching size range of 1 to $6 \mathrm{~nm}$.

8. Explorations of the PHA technique. The PHA is a promising technique for sizing of transient cluster distributions. While some reports on the technique exist, more work could be done explore fully the applicability and usability of the technique.

9. CPCs specialized for extremely cold or hot environments, such as a CPC built for sampling hot aerosol(e.g. by Collings et al. 2014). Bringing aerosol particles from an extreme temperature to another temperature, such as any combustion source, or from stratospheric temperatures to room temperature, can change the particle properties. The particles should be preferably measured at the temperature of their environment. 
10. Lightweight CPCs. No portable sub-3 nm CPCs have been reported, which limits their applicability mostly to stationary experiments, or moving platforms such as vans or aircrafts.

11. Low-cost CPCs. The applications for low-cost CPCs are vertical profile measurements for in which risks of losing the instruments are high, and dense measurement grids to spot nanoparticle formation hot spots for example in mega city or industrial environments.

12. Dilution sampling. Coincidence in CPC optics limits the accuracy at high particle concentrations (above approximately $10^{4} \mathrm{~cm}^{-3}$ ), while sub-3 nm particle concentrations can be extremely high, reaching even $10^{5}$ to $10^{7} \mathrm{~cm}^{-3}$. Controlled dilution with characterized size dependent losses would increase the accuracy of such experiments. Furthermore, dilution with dry air would reduce the variations in the cut-off of a DEG based CPC.

Acknowledgements

We thank Katrianne Lehtipalo for useful discussions, and the four reviewers for suggestions and corrections that significantly improved the manuscript.

\section{References}

Adachi, M., Okuyama, K., Seinfeld, J. H. (1992). Experimental studies on ion-induced nucleation. J Aerosol Sci 23:327-337.

Agarwal, J. K. and Sem, G. J. (1980). Continuous flow, single-particle-counting condensation nucleus counter. J Aerosol Sci 11:343-357.

Ahn, K. H. and Liu, B. Y. H. (1990a). Particle Activation and Droplet Growth-Processes in Condensation Nucleus Counter .1. Theoretical Background. J Aerosol Sci 21:249-261.

Ahn, K. H. and Liu, B. Y. H. (1990b). Particle Activation and Droplet Growth-Processes in Condensation Nucleus Counter .2. Experimental-Study. J Aerosol Sci 21:263-275.

Ahonen, L., Kangasluoma, J., Lehtipalo, K., Vehkamaki, H., Petäjä, T., Kulmala, M. (2019). Characterization of the effects caused by sample air humidity to the performance of a diethylene glycol based particle size magnifier. In preparation.

Ahonen, L. R., Kangasluoma, J., Lammi, J., Lehtipalo, K., Hameri, K., Petaja, T., Kulmala, M. (2017). First measurements of the number size distribution of $1-2 \mathrm{~nm}$ aerosol particles released from manufacturing processes in a cleanroom environment. Aerosol Sci Tech 51:685-693.

Aitken, J. (1880a). On Dusts, Fogs and Clouds. Nature Feb:384-385.

Aitken, J. (1880b). On Dusts, Fogs and Clouds. Proc. Roy. Soc. 11:11-14.

Alanen, J., Saukko, E., Lehtoranta, K., Murtonen, T., Timonen, H., Hillamo, R., Karjalainen, P., Kuuluvainen, H., Harra, J., Keskinen, J., Ronkko, T. (2015). The formation and physical properties of the particle emissions from a natural gas engine. Fuel 162:155-161. 
Amo-Gonzalez, M. and Perez, S. (2018). Planar Differential Mobility Analyzer with a Resolving Power of 110. Anal Chem 90:6735-6741.

Asbach, C., Schmitz, A., Schmidt, F., Monz, C., Todea, A. M. (2017). Intercomparison of a Personal CPC and Different Conventional CPCs. Aerosol Air Qual Res 17:1132-1141.

Attoui, M. (2018). Activation of sub $2 \mathrm{~nm}$ singly charged particles with butanol vapors in a boosted 3776 TSI CPC. J Aerosol Sci 126:47-57.

Baltzer, S., Onel, S., Weiss, M., Seipenbusch, M. (2014). Counting efficiency measurements for a new condensation particle counter. J Aerosol Sci 70:11-14.

Barmpounis, K., Ranjithkumar, A., Schmidt-Ott, A., Attoui, M., Biskos, G. (2018). Enhancing the detection efficiency of condensation particle counters for sub-2 nm particles. J Aerosol Sci 117:44-53.

Bartz, H., Fissan, H., Helsper, C., Kousaka, Y., Okuyama, K., Fukushima, N., Keady, P. B., Kerrigan, S., Fruin, S. A., Mcmurry, P. H., Pui, D. Y. H., Stolzenburg, M. R. (1985). Response Characteristics for 4 Different Condensation Nucleus Counters to Particles in the 3-50 Nm Diameter Range. Journal of Aerosol Science 16:443-456.

Boies, A. M., Lei, P. Y., Calder, S., Shin, W. G., Girshick, S. L. (2011). Hot-Wire Synthesis of Gold Nanoparticles. Aerosol Sci Tech 45:654-663.

Bricard, J., Delattre, P., Madelaine, G., Pourprix, M. (1976). Detection of ultra-fine particles by means of a continuous flux condensation nuclei counter. Fine Particles, Academic Press, New York:565-580.

Brockmann, J. E. (1981). Coagulation and deposition of ultrafine aerosols in turbulent pipe flow. Ph.D. thesis, Mechanical Engineering Department, University of Minnesota, Minneapolis.

Brunelli, N. A., Flagan, R. C., Giapis, K. P. (2009). Radial Differential Mobility Analyzer for One Nanometer Particle Classification. Aerosol Sci Tech 43:53-59.

Buckley, D. T. and Hogan, C. J. (2017). Determination of the transfer function of an atmospheric pressure drift tube ion mobility spectrometer for nanoparticle measurements. Analyst 142:1800-1812.

Cai, R., Chen, D. R., Hao, J., Jiang, J. (2017a). A miniature cylindrical differential mobility analyzer for sub-3 nm particle sizing. J Aerosol Sci 106:111-119. 
Cai, R., Mirme, S., Jiang, J., Kangasluoma, J. (2019). Parameters to determine the optimum performance of electrical mobility spectrometers for measurement of particle size distributions down to the cluster size. J Aerosol Sci 127:102-115.

Cai, R., Yang, D., Ahonen, L. R., Shi, L., Korhonen, F., Petäjä, T., Zheng, J., Kangasluoma, J., Jiang, J. (2018). Data inversion methods to determine sub-3 nm aerosol size distributions using the Particle Size Magnifier. Atmos Meas Tech 11:4477-4491.

Cai, R. L., Yang, D. S., Fu, Y. Y., Wang, X., Li, X. X., Ma, Y., Hao, J. M., Zheng, J., Jiang, J. K. (2017b). Aerosol surface area concentration: a governing factor in new particle formation in Beijing. Atmos Chem Phys 17:12327-12340.

Carbone, F., Attoui, M., Gomez, A. (2016). Challenges of measuring nascent soot in flames as evidenced by highresolution differential mobility analysis. Aerosol Sci Tech 50:740-757.

Cloupeau, M. and Prunet-Foch, B. (1994). Electrohydrodynamic Spraying Functioning Modes - a Critical-Review. J Aerosol Sci 25:1021-1036.

Collings, N., Rongchai, K., Symonds, J. P. R. (2014). A condensation particle counter insensitive to volatile particles. J Aerosol Sci 73:27-38.

Coulier, P. J. (1875a). Note sur une nouvelle propriete de I'air. J. de Pharmacie et de Chimie, Paris Ser. 4, 22:165 $-173$.

Coulier, P. J. (1875b). Note sur une nouvelle propriete de I'air. J. de Pharmacie et de Chimie, Paris Ser. 4, 22:254 $-255$.

El Golli, S., Madelaine, G., Turpin, P. Y., Bricard, J. (1975). Recent Advances in Photoelectric Aerosol Measurements. Water Air Soil Poll 5:11-38.

Enroth, J., Kangasluoma, J., Korhonen, F., Hering, S., Picard, D., Lewis, G., Attoui, M., Petaja, T. (2018). On the time response determination of condensation particle counters. Aerosol Sci Tech 52:778-787.

Fang, J. X., Wang, Y., Kangasluoma, J., Attoui, M., Junninen, H., Kulmala, M., Petaja, T., Biswas, P. (2017). Cluster formation mechanisms of titanium dioxide during combustion synthesis: Observation with an APi-TOF. Aerosol Sci Tech 51:1071-1081.

Fang, J. X., Wang, Y., Kangasluoma, J., Attoui, M., Junninen, H., Kulmala, M., Petaja, T., Biswas, P. (2018). The initial stages of multicomponent particle formation during the gas phase combustion synthesis of mixed SiO2/TiO2. Aerosol Sci Tech 52:277-286. 
Feng, J. C., Huang, L. Y., Ludvigsson, L., Messing, M. E., Maisser, A., Biskos, G., Schmidt-Ott, A. (2016). General Approach to the Evolution of Singlet Nanoparticles from a Rapidly Quenched Point Source. J Phys Chem C 120:621-630.

Fernandéz de la Mora, J. (2011). Heterogeneous Nucleation with Finite Activation Energy and Perfect Wetting: Capillary Theory Versus Experiments with Nanometer Particles, and Extrapolations on the Smallest Detectable Nucleus. Aerosol Sci Tech 45:543-554.

Fernandéz de la Mora, J. (2017). Expanded flow rate range of high-resolution nanoDMAs via improved sample flow injection at the aerosol inlet slit. J Aerosol Sci 113:265-275.

Fernandez de la Mora, J. and Barrios-Collado, C. (2017). A bipolar electrospray source of singly charged salt clusters of precisely controlled composition. Aerosol Sci Tech 51:778-786.

Fernandéz de la Mora, J. and Kozlowski, J. (2013). Hand-held differential mobility analyzers of high resolution for 1-30 nm particles: Design and fabrication considerations. J Aerosol Sci 57:45-53.

Flagan, R. (1999). On Differential Mobility Analyzer Resolution. Aerosol Sci Tech 30:556-570.

Fletcher, N. H. (1958). Size Effect in Heterogeneous Nucleation. J Chem Phys 29:572-576.

Fu, Y., Xue, M., Cai, R., Kangasluoma, J., Jiang, J. (2019). Theoretical and experimental analysis of the core sampling method: reducing diffusional losses in aerosol sampling line. Aerosol Sci Tech 53:793-801.

Gamero-Castano, M. and Fernandéz de la Mora, J. (2000). A condensation nucleus counter (CNC) sensitive to singly charged sub-nanometer particles. J Aerosol Sci 31:757-772.

Gamero-Castano, M. and Fernandéz de la Mora, J. (2002). Ion-induced nucleation: Measurement of the effect of embryo's size and charge state on the critical supersaturation. J Chem Phys 117:3345-3353.

Hering, S. V., Lewis, G. S., Spielman, S. R., Eiguren-Fernandez, A. (2018). A MAGIC Concept for Self-Sustained, Water based, Ultrafine Particle Counting. Aerosol Sci Tech.

Hering, S. V., Lewis, G. S., Spielman, S. R., Eiguren-Fernandez, A., Kreisberg, N. M., Kuang, C., Attoui, M. (2017). Detection near 1-nm with a Laminar-Flow, Water-Based Condensation Particle Counter. Aerosol Sci Tech 51.

Hering, S. V., Spielman, S. R., Lewis, G. S. (2014). Moderated, Water-Based, Condensational Particle Growth in a Laminar Flow. Aerosol Sci Tech 48:401-408. 
Hering, S. V. and Stolzenburg, M. R. (2005). A method for particle size amplification by water condensation in a laminar, thermally diffusive flow. Aerosol Sci Tech 39:428-436.

Hering, S. V., Stolzenburg, M. R., Quant, F. R., Oberreit, D. R., Keady, P. B. (2005). A laminar-flow, water-based condensation particle counter (WCPC). Aerosol Sci Tech 39:659-672.

Hietikko, R., Kuuluvainen, H., Harrison, R. M., Portin, H., Timonen, H., Niemi, J. V., Ronkko, T. (2018). Diurnal variation of nanocluster aerosol concentrations and emission factors in a street canyon. Atmos Environ 189:98106.

Hogan, C. J. and Fernandez de la Mora, J. (2009). Tandem ion mobility-mass spectrometry (IMS-MS) study of ion evaporation from ionic liquid-acetonitrile nanodrops. Phys Chem Chem Phys 11:8079-8090.

Hwang, I. and Ahn, H. K. (2017). Performance evaluation of conventional type conductive cooling continuous flow compact water-based CPC (Hy-WCPC). J Aerosol Sci 113:12-19.

lida, K., Stolzenburg, M. R., McMurry, P. H. (2009). Effect of Working Fluid on Sub-2 nm Particle Detection with a Laminar Flow Ultrafine Condensation Particle Counter. Aerosol Sci Tech 43:81-96.

lida, K., Stolzenburg, M. R., McMurry, P. H., Smith, J. N., Quant, F. R., Oberreit, D. R., Keady, P. B., EigurenFernandez, A., Lewis, G. S., Kreisberg, N. M., Hering, S. V. (2008). An ultrafine, water-based condensation particle counter and its evaluation under field conditions. Aerosol Sci Tech 42:862-871.

Ito, E., Seto, T., Otani, Y., Sakurai, H. (2011). Nucleation of Ethylene Glycol Vapor and Growth of Sub-10-nm Particles in Nanoparticle Size Magnifier. Aerosol Sci Tech 45:1250-1259.

Jiang, J. K., Attoui, M., Heim, M., Brunelli, N. A., McMurry, P. H., Kasper, G., Flagan, R. C., Giapis, K., Mouret, G. (2011a). Transfer Functions and Penetrations of Five Differential Mobility Analyzers for Sub-2 nm Particle Classification. Aerosol Sci Tech 45:480-492.

Jiang, J. K., Chen, M. D., Kuang, C. A., Attoui, M., McMurry, P. H. (2011b). Electrical Mobility Spectrometer Using a Diethylene Glycol Condensation Particle Counter for Measurement of Aerosol Size Distributions Down to $1 \mathrm{~nm}$. Aerosol Sci Tech 45:510-521.

Jiang, J. K., Zhao, J., Chen, M. D., Eisele, F. L., Scheckman, J., Williams, B. J., Kuang, C. A., McMurry, P. H. (2011c). First Measurements of Neutral Atmospheric Cluster and 1-2 nm Particle Number Size Distributions During Nucleation Events. Aerosol Sci Tech 45:Ii-V.

Kane, D., Daly, G. M., El-Shall, S. (1995). Condensation of Supersaturated Vapors on Benzene lons Generated by Resonant Two-Photon Ionization: A New Technique for Ion Nucleation. Journal of Physical Chemistry 99:78677870. 
Kangasluoma, J., Ahonen, L., Attoui, M., Vuollekoski, H., Kulmala, M., Petaja, T. (2015a). Sub-3nm Particle Detection with Commercial TSI 3772 and Airmodus A20 Fine Condensation Particle Counters. Aerosol Sci Tech 49:674-681.

Kangasluoma, J., Ahonen, L. R., Laurila, T., Cai, R., Enroth, J., Mazon, S., Korhonen, F., Aalto, P., Kulmala, M., Attoui, M., Petäjä, T. (2018). Laboratory verification of a new high flow differential mobility particle sizer, and field measurements in Hyytiälä. J Aerosol Sci 124:1-9.

Kangasluoma, J., Attoui, M., Junninen, H., Lehtipalo, K., Samodurov, A., Korhonen, F., Sarnela, N., Schmidt-Ott, A., Worsnop, D., Kulmala, M., Petaja, T. (2015b). Sizing of neutral sub $3 \mathrm{~nm}$ tungsten oxide clusters using Airmodus Particle Size Magnifier. J Aerosol Sci 87:53-62.

Kangasluoma, J., Attoui, M., Korhonen, F., Ahonen, L., Siivola, E., Petaja, T. (2016a). Characterization of a Herrmann-type high-resolution differential mobility analyzer. Aerosol Sci Tech 50:222-229.

Kangasluoma, J., Franchin, A., Duplissy, J., Ahonen, L., Korhonen, F., Attoui, M., Mikkila, J., Lehtipalo, K., Vanhanen, J., Kulmala, M., Petaja, T. (2016b). Operation of the Airmodus A11 nano Condensation Nucleus Counter at various inlet pressures and various operation temperatures, and design of a new inlet system. Atmos Meas Tech 9:2977-2988.

Kangasluoma, J., Hering, S., Picard, D., Lewis, G., Enroth, J., Korhonen, F., Kulmala, M., Sellegri, K., Attoui, M., Petaja, T. (2017). Characterization of three new condensation particle counters for sub-3 nm particle detection during the Helsinki CPC workshop: the ADI versatile water CPC, TSI 3777 nano enhancer and boosted TSI 3010. Atmos Meas Tech 10:2271-2281.

Kangasluoma, J., Junninen, H., Lehtipalo, K., Mikkila, J., Vanhanen, J., Attoui, M., Sipila, M., Worsnop, D., Kulmala, M., Petaja, T. (2013). Remarks on Ion Generation for CPC Detection Efficiency Studies in Sub-3-nm Size Range. Aerosol Sci Tech 47:556-563.

Kangasluoma, J. and Kontkanen, J. (2017). On the sources of uncertainty in the sub-3 $\mathrm{nm}$ particle concentration measurement. J Aerosol Sci 112:34-51.

Kangasluoma, J., Kuang, C., Wimmer, D., Rissanen, M. P., Lehtipalo, K., Ehn, M., Worsnop, D. R., Wang, J., Kulmala, M., Petaja, T. (2014). Sub-3 nm particle size and composition dependent response of a nano-CPC battery. Atmos Meas Tech 7:689-700.

Kangasluoma, J., Samodurov, A., Attoui, M., Franchin, A., Junninen, H., Korhonen, F., Kurten, T., Vehkamaki, H., Sipila, M., Lehtipalo, K., Worsnop, D. R., Petaja, T., Kulmala, M. (2016c). Heterogeneous Nucleation onto Ions and Neutralized Ions: Insights into Sign-Preference. J Phys Chem C 120:7444-7450. 
Kebarle, P. and Verkerk, U. H. (2009). Electrospray: From lons in Solution to lons in the Gas Phase, What We Know Now. Mass Spectrom Rev 28:898-917.

Kesten, J., Reineking, A., Porstendorfer, J. (1991). Calibration of a TSI Model 3025 Ultrafine Condensation Particle Counter. Aerosol Sci Tech 15:107-111.

Kim, lida, K., Kuromiya, Y., Seto, T., Higashi, H., Otani, Y. (2015). Effect of Nucleation Temperature on Detecting Molecular Ions and Charged Nanoparticles with a Diethylene Glycol-Based Particle Size Magnifier. Aerosol Sci Tech 49:35-44.

Kim, Okuyama, K., Shimada, M. (2002). Performance of a mixing-type CNC for nanoparticles at low-pressure conditions. Journal of Aerosol Science 33:1389-1404.

Kim, C. S., Okuyama, K., de la Mora, J. F. (2003). Performance evaluation of an improved particle size magnifier (PSM) for single nanoparticle detection. Aerosol Sci Tech 37:791-803.

Kirkby, J., Curtius, J., Almeida, J., Dunne, E., Duplissy, J., Ehrhart, S., Franchin, A., Gagne, S., Ickes, L., Kurten, A., Kupc, A., Metzger, A., Riccobono, F., Rondo, L., Schobesberger, S., Tsagkogeorgas, G., Wimmer, D., Amorim, A., Bianchi, F., Breitenlechner, M., David, A., Dommen, J., Downard, A., Ehn, M., Flagan, R. C., Haider, S., Hansel, A., Hauser, D., Jud, W., Junninen, H., Kreissl, F., Kvashin, A., Laaksonen, A., Lehtipalo, K., Lima, J., Lovejoy, E. R., Makhmutov, V., Mathot, S., Mikkilä, J., Minginette, P., Mogo, S., Nieminen, T., Onnela, A., Pereira, P., Petäjä, T., Schnitzhofer, R., Seinfeld, J. H., Sipilä, M., Stozhkov, Y., Stratmann, F., Tome, A., Vanhanen, J., Viisanen, Y., Vrtala, A., Wagner, P. E., Walther, H., Weingartner, E., Wex, H., Winkler, P. M., Carslaw, K. S., Worsnop, D. R., Baltensperger, U., Kulmala, M. (2011). Role of sulphuric acid, ammonia and galactic cosmic rays in atmospheric aerosol nucleation. Nature 476:429-U477.

Kirkby, J., Duplissy, J., Sengupta, K., Frege, C., Gordon, H., Williamson, C., Heinritzi, M., Simon, M., Yan, C., Almeida, J., Trostl, J., Nieminen, T., Ortega, I. K., Wagner, R., Adamov, A., Amorim, A., Bernhammer, A. K., Bianchi, F., Breitenlechner, M., Brilke, S., Chen, X. M., Craven, J., Dias, A., Ehrhart, S., Flagan, R. C., Franchin, A., Fuchs, C., Guida, R., Hakala, J., Hoyle, C. R., Jokinen, T., Junninen, H., Kangasluoma, J., Kim, J., Krapf, M., Kurten, A., Laaksonen, A., Lehtipalo, K., Makhmutov, V., Mathot, S., Molteni, U., Onnela, A., Perakyla, O., Piel, F., Petaja, T., Praplan, A. P., Pringle, K., Rap, A., Richards, N. A. D., Riipinen, I., Rissanen, M. P., Rondo, L., Sarnela, N., Schobesberger, S., Scott, C. E., Seinfeld, J. H., Sipila, M., Steiner, G., Stozhkov, Y., Stratmann, F., Tome, A., Virtanen, A., Vogel, A. L., Wagner, A. C., Wagner, P. E., Weingartner, E., Wimmer, D., Winkler, P. M., Ye, P. L., Zhang, X., Hansel, A., Dommen, J., Donahue, N. M., Worsnop, D. R., Baltensperger, U., Kulmala, M., Carslaw, K. S., Curtius, J. (2016). Ion-induced nucleation of pure biogenic particles. Nature 533:521-+.

Kogan, Y. I. and Burnasheva, Z. A. (1960). Growth and Measurement of Condensation Nuclei in a Continuous Stream. Zhurnal Fizicheskoi Khimii 34:2630-2639.

Kontkanen, J., Lehtipalo, K., Ahonen, L., Kangasluoma, J., Manninen, H. E., Hakala, J., Rose, C., Sellegri, K., Xiao, S., Wang, L., Qi, X. M., Nie, W., Ding, A. J., Yu, H., Lee, S., Kerminen, V. M., Petaja, T., Kulmala, M. (2017). Measurements of sub-3nm particles using a particle size magnifier in different environments: from clean mountain top to polluted megacities. Atmos Chem Phys 17:2163-2187. 
Kousaka, Y., Niida, T., Okuyama, K., Tanaka, H. (1982). Development of a Mixing Type Condensation Nucleus Counter. Journal of Aerosol Science 13:231-240.

Kuang, C. (2018). A diethylene glycol condensation particle counter for rapid sizing of sub-3nm atmospheric clusters. Aerosol Sci Tech 10:1112-1119.

Kuang, C., Chen, M., Zhao, J., Smith, J., McMurry, P. H., Wang, J. (2012a). Size and time-resolved growth rate measurements of 1 to $5 \mathrm{~nm}$ freshly formed atmospheric nuclei. Atmos Chem Phys 12:3573-3589.

Kuang, C. A., Chen, M. D., McMurry, P. H., Wang, J. (2012b). Modification of Laminar Flow Ultrafine Condensation Particle Counters for the Enhanced Detection of $1 \mathrm{~nm}$ Condensation Nuclei. Aerosol Sci Tech 46:309-315.

Kulmala, M., Kontkanen, J., Junninen, H., Lehtipalo, K., Manninen, H. E., Nieminen, T., Petaja, T., Sipila, M., Schobesberger, S., Rantala, P., Franchin, A., Jokinen, T., Jarvinen, E., Aijala, M., Kangasluoma, J., Hakala, J., Aalto, P. P., Paasonen, P., Mikkila, J., Vanhanen, J., Aalto, J., Hakola, H., Makkonen, U., Ruuskanen, T., Mauldin, R. L., Duplissy, J., Vehkamaki, H., Back, J., Kortelainen, A., Riipinen, I., Kurten, T., Johnston, M. V., Smith, J. N., Ehn, M., Mentel, T. F., Lehtinen, K. E. J., Laaksonen, A., Kerminen, V. M., Worsnop, D. R. (2013). Direct Observations of Atmospheric Aerosol Nucleation. Science 339:943-946.

Kulmala, M., Mordas, G., Petaja, T., Gronholm, T., Aalto, P. P., Vehkamaki, H., Hienola, A. I., Herrmann, E., Sipila, M., Riipinen, I., Manninen, H. E., Hameri, K., Stratmann, F., Bilde, M., Winkler, P. M., Birmili, W., Wagner, P. E. (2007). The condensation particle counter battery (CPCB): A new tool to investigate the activation properties of nanoparticles. J Aerosol Sci 38:289-304.

Kupc, A., Bischof, O., Tritscher, T., Beeston, M., Krinke, T., Wagner, P. E. (2013a). Laboratory Characterization of a New Nano-Water-Based CPC 3788 and Performance Comparison to an Ultrafine Butanol-Based CPC 3776. Aerosol Sci Tech 47:183-191.

Kupc, A., Winkler, P. M., Vrtala, A., Wagner, P. (2013b). Unusual Temperature Dependence of Heterogeneous Nucleation of Water Vapor on Ag Particles. Aerosol Sci Tech 47:I-Iv.

Kurten, A., Curtius, J., Nillius, B., Borrmann, S. (2005). Characterization of an automated, water-based expansion condensation nucleus counter for ultrafine particles. Aerosol Sci Tech 39:1174-1183.

Kwon, H. B., Yoo, S. H., Hong, U. S., Kim, K., Han, J., Kim, M. K., Kang, D. H., Hwang, J., Kim, Y. J. (2019). MEMSbased condensation particle growth chip for optically measuring the airborne nanoparticle concentration. Lab on a Chip.

Lehtipalo, K., Sipila, M., Riipinen, I., Nieminen, T., Kulmala, M. (2009). Analysis of atmospheric neutral and charged molecular clusters in boreal forest using pulse-height CPC. Atmos Chem Phys 9:4177-4184. 
Lewis, G. S. and Hering, S. (2013). Minimizing Concentration Effects in Water-Based, Laminar-Flow Condensation Particle Counters. Aerosol Sci Tech 47:645-654.

Li, C. X. and Hogan, C. J. (2017). Vapor specific extents of uptake by nanometer scale charged particles. Aerosol Sci Tech 51:653-664.

Liu, B. Y. H. and Kim, C. S. (1977). On the counting efficiency of condensation nuclei counters. Atmos Environ 11:1097-1100.

Liu, B. Y. H. and Pui, D. Y. H. (1974). Submicron Aerosol Standard and Primary, Absolute Calibration of Condensation Nuclei Counter. J Colloid Interf Sci 47:155-171.

Liu, W., Kaufman, S. L., Osmondson, B. L., Sem, G. J., Quant, F. R., Oberreit, D. R. (2006). Water-based condensation particle counters for environmental monitoring of ultrafine particles. J Air Waste Manage 56:444455.

Madelaine, G. and Metayer, Y. (1980). Note. J Aerosol Sci 11:358.

Magnusson, L. E., Koropchak, J. A., Anisimov, M. P., Poznjakovskiy, V. M., de la Mora, J. F. (2003). Correlations for vapor nucleating critical embryo parameters. J Phys Chem Ref Data 32:1387-1410.

Maisser, A., Barmpounis, K., Attoui, M. B., Biskos, G., Schmidt-Ott, A. (2015a). Atomic Cluster Generation with an Atmospheric Pressure Spark Discharge Generator. Aerosol Sci Tech 49:886-894.

Maisser, A., Thomas, J. M., Larriba-Andaluz, C., He, S., Hogan, C. J. (2015b). The mass-mobility distributions of ions produced by a Po-210 source in air. J Aerosol Sci 90:36-50.

Marti, J. J., Weber, R. J., Saros, M. T., Vasiliou, J. G., McMurry, P. H. (1996). Modification of the TSI 3025 condensation particle counter for pulse height analysis. Aerosol Sci Tech 25:214-218.

Mavliev, R. (2002). Turbulent mixing condensation nucleus counter. Atmos Res 62:303-314.

Mavliev, R. and Wang, H. C. (2000). Design and performance characteristics of a turbulent mixing condensation nuclei counter. J Aerosol Sci 31:933-944.

McDermott, W. T., Ockovic, R. C., Stolzenburg, M. R. (1991). Counting Efficiency of an Improved 30-a Condensation Nucleus Counter. Aerosol Sci Tech 14:278-287.

McMurry, P. H. (2000). The History of Condensation Nucleus Counters. Aerosol Sci Tech 33:297-322. 
Mertes, S., Schroder, F., Wiedensohler, A. (1995). The Particle-Detection Efficiency Curve of the Tsi-3010 Cpc as a Function of the Temperature Difference between Saturator and Condenser. Aerosol Sci Tech 23:257-261.

Metayer, Y. and Madelaine, G. (1980). ON THE COUNTING EFFICIENCY OF A CONTINUOUS FLOW CONDENSATION NUCLEI COUNTER. Studies in Environmental Science 8:273-278.

Mordas, G., Kulmala, M., Petaja, T., AAlto, P. P., Matulevicius, V., Grigoraitis, V., Ulevicius, V., Grauslys, V., Ukkonen, A., Hameri, K. (2005). Design and performance characteristics of a condensation particle counter UF02proto. Boreal Environ Res 10:543-552.

Mordas, G., Manninen, H. E., Petaja, T., Aalto, P. P., Hameri, K., Kulmala, M. (2008a). On operation of the ultrafine water-based CPC TSI3786 and comparison with other TSI models (TSI3776, TSI3772, TSI3025, TSI3010, TSI3007). Aerosol Sci Tech 42:152-158.

Mordas, G., Sipila, M., Kulmala, M. (2008b). Nanometer particle detection by the condensation particle counter UF-02proto. Aerosol Sci Tech 42:521-527.

Niesser, R. and Helsper, C. (1985). Application of a multistep condensation nuclei counter as a detector for a particle surface composition. J Aerosol Sci 16:201-209.

Nolan, P. J. and Kennan, E. L. (1949). Condensation Nuclei from Hot Platinum: Size, Coagulation Coefficient and Charge-Distribution. Proceedings of the Royal Irish Academy. Section A: Mathematical and Physical Sciences 52:171-190.

Nosko, O., Vanhanen, J., Olofsson, U. (2017). Emission of 1.3-10 nm airborne particles from brake materials. Aerosol Sci Tech 51:91-96.

O'Dowd, C. D., Aalto, P. P., Yoon, Y. J., Hämeri, K. (2004). The use of the pulse height analyser ultrafine condensation particle counter (PHA-UCPC) technique applied to sizing of nucleation mode particles of differing chemical composition. J Aerosol Sci 35:205-216.

Oberreit, D., Rawat, V. K., Larriba-Andaluz, C., Ouyang, H., McMurry, P. H., Hogan, C. J. (2015). Analysis of heterogeneous water vapor uptake by metal iodide cluster ions via differential mobility analysis-mass spectrometry. J Chem Phys 143.

Okuyama, K., Kousaka, Y., Motouchi, T. (1984). Condensational Growth of Ultrafine Aerosol-Particles in a New Particle-Size Magnifier. Aerosol Sci Tech 3:353-366.

Owen, G. (1903). XXXVIII. On the condensation nuclei produced in air and hydrogen by heating a platinum wire. The London, Edinburgh, and Dublin Philosophical Magazine and Journal of Science 6:306-315. 
Pedder, M. A. (1971). Measurement of Size and Diffusion Characteristics of Aerosols with Particle Sizes Less Than 0.01 Mum Using Pollak Condensation Nucleus Counter. J Phys D Appl Phys 4:531-\&.

Pedder, M. A. (1974). Smallest Particles Detected by Condensation Nucleus Counters. Atmos Environ 8:10611062.

Peineke, C., Attoui, M., Robles, R., Reber, A. C., Khanna, S. N., Schmidt-Ott, A. (2009). Production of equal sized atomic clusters by a hot wire. J Aerosol Sci 40:423-430.

Peineke, C. and Schmidt-Ott, A. (2008). Explanation of charged nanoparticle production from hot surfaces. J Aerosol Sci 39:244-252.

Petäjä, T., Mordas, G., Manninen, H., Aalto, P. P., Hämeri, K., Kulmala, M. (2006). Detection efficiency of a waterbased TSI Condensation Particle Counter 3785. Aerosol Sci Tech 40:1090-1097.

Picard, D., Attoui, M., Sellegri, K. (2018). B3010: A Boosted TSI 3010 CPC for Airborne Studies. Atmospheric measurement Techniques Discussions.

Pinterich, T., Vrtala, A., Kaltak, M., Kangasluoma, J., Lehtipalo, K., Petaja, T., Winkler, P. M., Kulmala, M., Wagner, P. E. (2016). The versatile size analyzing nuclei counter (vSANC). Aerosol Sci Tech 50:947-958.

Pollak, L. W. and Daly, J. (1957). A condensation nucleus counter with stereo photomicrograph recording. Geofis. Pura Appl. 36:27-34.

Porstendörfer, J., Scheibel, H. G., Pohl, F. G., Preining, O., Reischl, G., Wagner, P. E. (1985). Heterogeneous Nucleation of Water-Vapor on Monodispersed Ag and Nacl Particles with Diameters between 6 and $18 \mathrm{Nm}$. Aerosol Sci Tech 4:65-79.

Rabeony, H. and Mirabel, P. (1987). Experimental study of vapor nucleation on ions. Journal of Physical Chemistry 91:1815-1818.

Riipinen, I., Manninen, H. E., Yli-Juuti, T., Boy, M., Sipila, M., Ehn, M., Junninen, H., Petaja, T., Kulmala, M. (2009). Applying the Condensation Particle Counter Battery (CPCB) to study the water-affinity of freshly-formed 2-9 nm particles in boreal forest. Atmos Chem Phys 9:3317-3330.

Romay, F. J., Collins, A. M., Dick, W. D., Li, L., Fandrey, C. W., Liu, B. Y. H. (2016). Water-based single-flow mixing condensation particle counter. Aerosol Sci Tech 50:1320-1326.

Rosell-Llompart, J., Loscertales, I. G., Bingham, D., Fernandéz de la Mora, J. (1996). Sizing nanoparticles and ions with a short differential mobility analyzer. J Aerosol Sci 27:695-719. 
Rönkkö, T., Kuuluvainen, H., Karjalainen, P., Keskinen, J., Hillamo, R., Niemi, J. V., Pirjola, L., Timonen, H. J., Saarikoski, S., Saukko, E., Jarvinen, A., Silvennoinen, H., Rostedt, A., Olin, M., Yli-Ojanpera, J., Nousiainen, P., Kousa, A., Dal Maso, M. (2017). Traffic is a major source of atmospheric nanocluster aerosol. P Natl Acad Sci USA 114:7549-7554.

Santos, J. P., Hontanon, E., Ramiro, E., Alonso, M. (2009). Performance evaluation of a high-resolution parallelplate differential mobility analyzer. Atmos Chem Phys 9:2419-2429.

Saros, M. T., Weber, R. J., Marti, J. J., McMurry, P. H. (1996). Ultrafine aerosol measurement using a condensation nucleus counter with pulse height analysis. Aerosol Science and Technology 25:200-213.

Scheibel, H. G. and Porstendörfer, J. (1983). Generation of Monodisperse Ag-Aerosol and Nacl-Aerosol with Particle Diameters between 2-Nm and 300-Nm. J Aerosol Sci 14:113-\&.

Scheibel, H. G. and Porstendörfer, J. (1986a). Counting Efficiency and Detection Limit of Condensation Nuclei Counters for Submicrometer Aerosols. I.

Theoretical Evaluation of the Influence of Heterogeneous Nucleation and Wall Losses. J Colloid Interf Sci 109:261-273.

Scheibel, H. G. and Porstendörfer, J. (1986b). Counting Efficiency and Detection Limit of Condensation Nuclei Counters for Submicrometer Aerosols. II. Measurements with Monodisperse Hydrophobic Ag and Hygroscopic $\mathrm{NaCl}$ Aerosols with Particle Diameters between 2 and 100 nm. J Colloid Interf Sci 109:275-291.

Scheibel, H. G. and Porstendörfer, J. (1986c). Counting Efficiency and Detection Limits of Condensation Nuclei Counters for Submicrometer Aerosols (Part-I and Part-li) - Reply. J Colloid Interf Sci 109:294-294.

Seto, T., Okuyama, K., de Juan, L., Fernandéz de la Mora, J. (1997). Condensation of supersaturated vapors on monovalent and divalent ions of varying size. Journal of Physical Chemistry 107:1576-1585.

Sgro, L. A. and Fernandéz de la Mora, J. (2004). A simple turbulent mixing CNC for charged particle detection down to $1.2 \mathrm{~nm}$. Aerosol Sci Tech 38:1-11.

Sinclair, D. (1981). Particle size sensitivity of condensation nucleus counters. Atmos Environ 16:955-958.

Sinclair, D. and Hoopes, G. S. (1975). A continuous flow condensation nucleus counter. J Aerosol Sci 6:1-7.

Sipilä, M., Lehtipalo, K., Attoui, M., Neitola, K., Petaja, T., Aalto, P. P., O'Dowd, C. D., Kulmala, M. (2009). Laboratory Verification of PH-CPC's Ability to Monitor Atmospheric Sub-3 nm Clusters. Aerosol Sci Tech 43:126135. 
Sipilä, M., Lehtipalo, K., Kulmala, M., Petaja, T., Junninen, H., Aalto, P. P., Manninen, H. E., Kyro, E. M., Asmi, E., Riipinen, I., Curtius, J., Kurten, A., Borrmann, S., O'Dowd, C. D. (2008). Applicability of condensation particle counters to measure atmospheric clusters. Atmos Chem Phys 8:4049-4060.

Steiner, G., Franchin, A., Kangasluoma, J., Kerminen, V. M., Kulmala, M., Petaja, T. (2017). Production of neutral molecular clusters by controlled neutralization of mobility standards. Aerosol Sci Tech 51:946-955.

Steiner, G., Jokinen, T., Junninen, H., Sipila, M., Petaja, T., Worsnop, D., Reischl, G. P., Kulmala, M. (2014). HighResolution Mobility and Mass Spectrometry of Negative lons Produced in a Am-241 Aerosol Charger. Aerosol Sci Tech 48:261-270.

Steiner, G. and Reischl, G. P. (2012). The effect of carrier gas contaminants on the charging probability of aerosols under bipolar charging conditions. J Aerosol Sci 54:21-31.

Stolzenburg, M. R. (1986). Counting Efficiency and Detection Limit of Condensation Nuclei Counters for Submicrometer Aerosols (Part-I and Part-li) - Comments. J Colloid Interf Sci 109:292-293.

Stolzenburg, M. R. and McMurry, P. H. (1984). A theoretical model for an ultrafine aerosol condensation nucleus counter, in Aerosols, (Edited by Liu, B. Y. H., Pui, D. Y. H. and Fissan, H. J.). Elsevier, New York.

Stolzenburg, M. R. and McMurry, P. H. (1991). An Ultrafine Aerosol Condensation Nucleus Counter. Aerosol Sci Tech 14:48-65.

Stolzenburg, M. R. and McMurry, P. H. (2008). Equations governing single and tandem DMA configurations and a new lognormal approximation to the transfer function. Aerosol Sci Tech 42:421-432.

Stolzenburg, M. R., Scheckman, J. H. T., Attoui, M., Han, H. S., McMurry, P. H. (2018). Characterization of the TSI model 3086 differential mobility analyzer for classifying aerosols down to $1 \mathrm{~nm}$. Aerosol Sci Tech 52:748-756.

Strey, R., Wagner, P. E., Schmeling, T. (1986). Homogeneous Nucleation Rates for N-Alcohol Vapors Measured in a 2-Piston Expansion Chamber. J Chem Phys 84:2325-2335.

Strey, R., Wagner, P. E., Viisanen, Y. (1994). The Problem of Measuring Homogeneous Nucleation Rates and the Molecular Contents of Nuclei - Progress in the Form of Nucleation Pulse Measurements. Journal of Physical Chemistry 98:7748-7758.

Takegawa, N., lida, K., Sakurai, H. (2017). Modification and laboratory evaluation of a TSI ultrafine condensation particle counter (Model 3776) for airborne measurements. Aerosol Sci Tech 51:235-245. 
Tauber, C., Brilke, S., Wlastis, P. J., Bauer, P. S., Köberl, G., Steiner, G., Winkler, P. M. (2019a). Humidity effects on the detection of soluble and insoluble nanoparticles in butanol operated condensation particle counters. Atmospheric measurement Techniques Discussions.

Tauber, C., Chen, X. S., Wagner, P. E., Winkler, P. M., Hogan, C. J., Maisser, A. (2018). Heterogeneous Nucleation onto Monoatomic lons: Support for the Kelvin-Thomson Theory. Chemphyschem 19:3144-3149.

Tauber, C., Steiner, G., Winkler, P. M. (2019b). Determination from Quantitative Intercomparison between Expansion and Laminar Flow Type Condensation Particle Counter. Aerosol Sci Tech.

Ude, S. and Fernandez de la Mora, J. (2005). Molecular monodisperse mobility and mass standards from electrosprays of tetra-alkyl ammonium halides. J Aerosol Sci 36:1224-1237.

Wagner, P. E. (1985). A Constant-Angle Mie Scattering Method (Cams) for Investigation of Particle Formation Processes. J Colloid Interf Sci 105:456-467.

Wagner, R., Yan, C., Lehtipalo, K., Duplissy, J., Nieminen, T., Kangasluoma, J., Ahonen, L. R., Dada, L., Kontkanen, J., Manninen, H. E., Dias, A., Amorim, A., Bauer, P. S., Bergen, A., Bernhammer, A. K., Bianchi, F., Brilke, S., Mazon, S. B., Chen, X. M., Draper, D. C., Fischer, L., Frege, C., Fuchs, C., Garmash, O., Gordon, H., Hakala, J., Heikkinen, L., Heinritzi, M., Hofbauer, V., Hoyle, C. R., Kirkby, J., Kurten, A., Kvashnin, A. N., Laurila, T., Lawler, M. J., Mai, H. J., Makhmutov, V., Mauldin, R. L., Molteni, U., Nichman, L., Nie, W., Ojdanic, A., Onnela, A., Piel, F., Quelever, L. L. J., Rissanen, M. P., Sarnela, N., Schallhart, S., Sengupta, K., Simon, M., Stolzenburg, D., Stozhkov, Y., Trostl, J., Viisanen, Y., Vogel, A. L., Wagner, A. C., Xiao, M., Ye, P., Baltensperger, U., Curtius, J., Donahue, N. M., Flagan, R. C., Gallagher, M., Hansel, A., Smith, J. N., Tome, A., Winkler, P. M., Worsnop, D., Ehn, M., Sipila, M., Kerminen, V. M., Petaja, T., Kulmala, M. (2017). The role of ions in new particle formation in the CLOUD chamber. Atmos Chem Phys 17:15181-15197.

Wang, J., McNeill, V. F., Collins, D. R., Flagan, R. C. (2002). Fast Mixing Condensation Nucleus Counter: Application to Rapid Scanning Differential Mobility Analyzer Measurements. Aerosol Sci Tech 36:678-689.

Wang, Y., Kangasluoma, J., Attoui, M., Fang, J., Junninen, H., Kulmala, M., Petaja, T., Biswas, P. (2017a). The high charge fraction of flame-generated particles in the size range below $3 \mathrm{~nm}$ measured by enhanced particle detectors. Combust Flame 176:72-80.

Wang, Y., Kangasluoma, J., Attoui, M., Fang, J. X., Junninen, H., Kulmala, M., Petaja, T., Biswas, P. (2017b). Observation of incipient particle formation during flame synthesis by tandem differential mobility analysis-mass spectrometry (DMA-MS). P Combust Inst 36:745-752.

Vanhanen, J., Mikkila, J., Lehtipalo, K., Sipila, M., Manninen, H. E., Siivola, E., Petaja, T., Kulmala, M. (2011). Particle Size Magnifier for Nano-CN Detection. Aerosol Sci Tech 45:533-542. 
Weber, R. J., Stolzenburg, M. R., Pandis, S. N., McMurry, P. H. (1998). Inversion of ultrafine condensation nucleus counter pulse height distributions to obtain nanoparticle (similar to 3-10 nm) size distributions. J Aerosol Sci 29:601-615.

Wiedensohler, A., Aalto, P., Covert, D., Heintzenberg, J., Mcmurry, P. H. (1994). Intercomparison of 4 Methods to Determine Size Distributions of Low-Concentration (Similar-to-100 Cm-3), Ultrafine Aerosols (3-Less-Than$D(P)$ Less-Than-10 Nm) with Illustrative Data from the Arctic. Aerosol Sci Tech 21:95-109.

Wiedensohler, A., Birmili, W., Nowak, A., Sonntag, A., Weinhold, K., Merkel, M., Wehner, B., Tuch, T., Pfeifer, S., Fiebig, M., Fjaraa, A. M., Asmi, E., Sellegri, K., Depuy, R., Venzac, H., Villani, P., Laj, P., Aalto, P., Ogren, J. A., Swietlicki, E., Williams, P., Roldin, P., Quincey, P., Huglin, C., Fierz-Schmidhauser, R., Gysel, M., Weingartner, E., Riccobono, F., Santos, S., Gruning, C., Faloon, K., Beddows, D., Harrison, R. M., Monahan, C., Jennings, S. G., O'Dowd, C. D., Marinoni, A., Horn, H. G., Keck, L., Jiang, J., Scheckman, J., McMurry, P. H., Deng, Z., Zhao, C. S., Moerman, M., Henzing, B., de Leeuw, G., Loschau, G., Bastian, S. (2012). Mobility particle size spectrometers: harmonization of technical standards and data structure to facilitate high quality long-term observations of atmospheric particle number size distributions. Atmos Meas Tech 5:657-685.

Wiedensohler, A., Orsini, D., Covert, D. S., Coffmann, D., Cantrell, W., Havlicek, M., Brechtel, F. J., Russell, L. M., Weber, R. J., Gras, J., Hudson, J. G., Litchy, M. (1997). Intercomparison study of the size-dependent counting efficiency of 26 condensation particle counters. Aerosol Sci Tech 27:224-242.

Viisanen, Y. and Strey, R. (1994). Homogeneous Nucleation Rates for N-Butanol. J Chem Phys 101:7835-7843.

Wilson, C. T. R. (1897). Condensation of Water Vapour in the Presence of Dust-Free Air and other Gases. Philosophical Transactions of the Royal Society of London 189:265-307.

Wilson, C. T. R. (1899). On the condensation nuclei produced in gases by the action of röntgen rays, uranium rays, ultra-violet light, and other agents. Philosophical Transactions of the Royal Society of London 192:403-453.

Wilson, J. C., Hyun, J. H., Blackshear, E. D. (1983). The Function and Response of an Improved Stratospheric Condensation Nucleus Counter. J Geophys Res-Oceans 88:6781-6785.

Wimmer, D., Lehtipalo, K., Franchin, A., Kangasluoma, J., Kreissl, F., Kurten, A., Kupc, A., Metzger, A., Mikkila, J., Petaja, T., Riccobono, F., Vanhanen, J., Kulmala, M., Curtius, J. (2013). Performance of diethylene glycol-based particle counters in the sub-3 nm size range. Atmos Meas Tech 6:1793-1804.

Wimmer, D., Lehtipalo, K., Nieminen, T., Duplissy, J., Ehrhart, S., Almeida, J., Rondo, L., Franchin, A., Kreissl, F., Bianchi, F., Manninen, H. E., Kulmala, M., Curtius, J., Petaja, T. (2015). Technical Note: Using DEG-CPCs at upper tropospheric temperatures. Atmos Chem Phys 15:7547-7555.

Winkler, P. M., Steiner, G., Vrtala, A., Reischl, G. P., Kulmala, M., Wagner, P. E. (2011). Unary and Binary Heterogeneous Nucleation of Organic Vapors on Monodisperse WOx Seed Particles with Diameters Down to 1.4 nm. Aerosol Sci Tech 45:493-498. 
Winkler, P. M., Steiner, G., Vrtala, A., Vehkamaki, H., Noppel, M., Lehtinen, K. E. J., Reischl, G. P., Wagner, P. E., Kulmala, M. (2008a). Heterogeneous nucleation experiments bridging the scale from molecular ion clusters to nanoparticles. Science 319:1374-1377.

Winkler, P. M., Vrtala, A., Steiner, G., Wimmer, D., Vehkamaki, H., Lehtinen, K. E. J., Reischl, G. P., Kulmala, M., Wagner, P. E. (2012). Quantitative Characterization of Critical Nanoclusters Nucleated on Large Single Molecules. Phys Rev Lett 108.

Winkler, P. M., Vrtala, A., Wagner, P. E. (2008b). Condensation particle counting below $2 \mathrm{~nm}$ seed particle diameter and the transition from heterogeneous to homogeneous nucleation. Atmos Res 90:125-131.

Yoo, S. H., Kwon, H. B., S., H. U., Kang, D. H., Lee, S. M., Han, J., Hwang, J., Kim, Y. J. (2019). MEMS-based condensation particle counter for real-time monitoring of airborne ultrafine particles at a point of interest. Atmospheric measurement Techniques Discussions. 